Pacific Northwest

National Laboratory

Operated by Battelle for the

U.S. Department of Energy

\title{
Dangerous Waste Characteristics of Contract-Hanford Transuranic Mixed Wastes from Hanford Tanks
}

\author{
J.M. Tingey \\ G.H. Bryan \\ J.R. Deschane
}

October 2004

\footnotetext{
Prepared for the U.S. Department of Energy
} under Contract DE-AC05-76RL01830 


\title{
DISCLAIMER
}

This report was prepared as an account of work sponsored by an agency of the United States Government. Neither the United States Government nor any agency thereof, nor Battelle Memorial Institute, nor any of their employees, makes any warranty, express or implied, or assumes any legal liability or responsibility for the accuracy, completeness, or usefulness of any information, apparatus, product, or process disclosed, or represents that its use would not infringe privately owned rights. Reference herein to any specific commercial product, process, or service by trade name, trademark, manufacturer, or otherwise does not necessarily constitute or imply its endorsement, recommendation, or favoring by the United States Government or any agency thereof, or Battelle Memorial Institute. The views and opinions of authors expressed herein do not necessarily state or reflect those of the United States Government or any agency thereof.

\author{
PACIFIC NORTHWEST NATIONAL LABORATORY \\ operated by \\ BATTELLE \\ for the \\ UNITED STATES DEPARTMENT OF ENERGY \\ under Contract DE-AC06-76RL01830
}

This document was printed on recycled paper. 


\title{
Dangerous Waste Characteristics of Contact-Handled Transuranic Mixed Wastes from Hanford Tanks
}

\author{
JM Tingey \\ GH Bryan \\ JR Deschane
}

October 2004

Prepared for the U.S. Department of Energy

under Contract DE-AC05-76RL01830 


\section{Executive Summary}

Existing analytical data from samples taken from Hanford tanks designated as potentially containing transuranic mixed process wastes, along with process knowledge of the wastes transferred to these tanks, have been reviewed to determine whether the dangerous waste characteristics currently assigned to all waste in Hanford underground storage tanks are applicable to these wastes. Supplemental technologies are being examined to accelerate the Hanford tank waste cleanup mission and to treat the waste in the safest and most efficient way. To date, 11 Hanford tanks have been designated as potentially containing contact-handled $(\mathrm{CH})$ transuranic mixed (TRUM) wastes. The CH-TRUM wastes are found in singleshell tanks (SSTs) B-201 through B-204, T-201 through T-204, T-104, T-110, and T-111. Methods and equipment to solidify and package the CH-TRUM wastes are part of the supplemental technologies being evaluated. The resulting packages and wastes must be acceptable for disposal at the Waste Isolation Pilot Plant (WIPP).

The 11 tanks reviewed were categorized into three groups based on their process history and the Best Basis Inventory. These three categories are T Farm 100 series tanks receiving first-cycle decontamination waste from the $\mathrm{BiPO}_{4}$ process, T Farm 100 series tanks receiving second-cycle waste from the $\mathrm{BiPO}_{4}$ process and lanthanum fluoride finishing waste, and B- and T-200 series tanks receiving lanthanum fluoride finishing waste.

The dangerous waste characteristics being considered include ignitability (D001), corrosivity (D002), reactivity (D003), and toxicity arising from the presence of 2,4,5-trichlorophenol at levels above the dangerous waste threshold (D041). The analytical data reviewed with respect to waste code D001 included differential scanning calorimetry (DSC) and the percent of the lower flammability limit (LFL) calculated from the composition of the headspace. Concentrations of sulfur, sulfate, cyanide, and the composition of headspace (vapor space) and DSC were reviewed for waste code D003; and $\mathrm{pH}$ was reviewed for D002. For waste code D041, the analytical data reviewed included the concentrations of 2,4,5-trichlorophenol, total organic carbon (TOC), and oxalate. Data on mercury concentrations in these wastes were also included. DSC results were used to determine the energetics of the tank wastes as a function of temperature. These results are summarized for each of the three tank categories.

No exothermic behavior was observed in the majority of the CH-TRUM wastes. Exothermic transitions were observed in a limited number of samples from Tank B-203, and a significant number of samples showed consistent exothermic behavior in Tanks B-202 and T-111. Exothermic transitions observed in these samples were generally broad peaks with small amplitudes at temperatures exceeding $200^{\circ} \mathrm{C}$, indicating that explosive reactions or ignition hazards at standard temperatures or pressures are unlikely (waste codes D001 and D003). The waste with the greatest potential for exothermic reactions is $\mathrm{T}-111$. The reactions are most likely due to the oxidation of organic compounds that are found primarily in the top section of the waste. If the wastes are wet, significant energy must be expended to remove the water from the waste before any reaction can occur.

Sulfur and sulfate analyses indicated that the majority of the sulfur in the waste is present as sulfate. Based on the $\mathrm{pH}$ of the tank wastes, the sulfate is stable and will not react to form sulfide; therefore, the CH-TRUM wastes are not sulfide-bearing wastes (waste code D003). A limited number of cyanide 
analyses were available for these tanks as well. Results indicated that these wastes do not contain a sufficient concentration of cyanide to be considered cyanide-bearing wastes (waste code D003).

Concentrations of the 2,4,5-trichlorophenol measured in the CH-TRUM wastes did not exceed the dangerous waste limits; therefore, the wastes do not meet the criteria of toxic characteristics based on this organic constituent (waste code D041). Oxalate and TOC data indicate that the majority of the organic carbon in the waste exists as oxalate.

The $\mathrm{pH}$ of the CH-TRUM wastes is too low to satisfy the $\mathrm{pH}$ criterion of a corrosive waste (waste code D002). Gas analysis of the headspace vapors in these tanks indicates that all of the toxic vapors except ammonia are well below the threshold limit value-time weighed average (TLV-TWA) (waste code D003). The tank wastes will need to be diluted prior to retrieval or other mitigation methods to meet this ammonia criterion on all of the wastes except those in the B- and T-200 series tanks.

Analysis of the existing characterization data from core, grab, and vapor samples from the $\mathrm{CH}$ TRUM wastes supports the removal of the dangerous waste codes for ignitability (D001), corrosivity (D002), and toxicity arising from the presence of 2,4,5-trichlorophenol (D041). For the B- and T-200 series tanks, the data also support the removal of the dangerous waste code for reactivity (D003). All constituents and properties were below the levels required to remove waste code D003 from Tanks T-104, T-110, and T-111 except ammonia, which exceeds the TLV in the headspaces of these tanks. 


\section{Table of Contents}

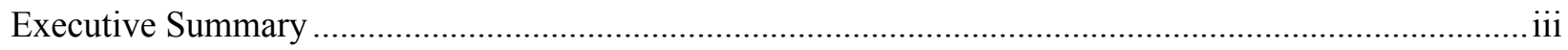

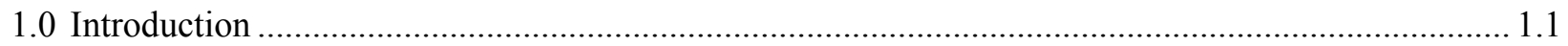

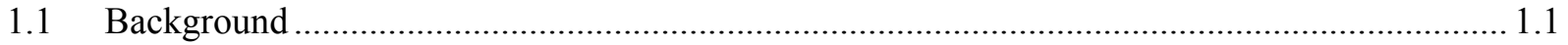

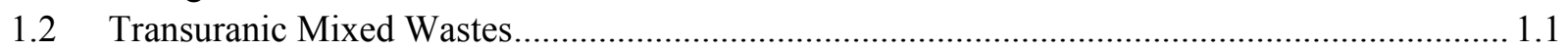

1.3 Dangerous Waste Characteristics................................................................................. 1.2

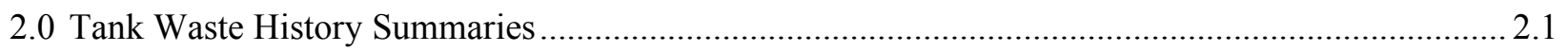

2.1 241-B-201 through B-204 and 241-T-201 through T-204 ................................................. 2.3

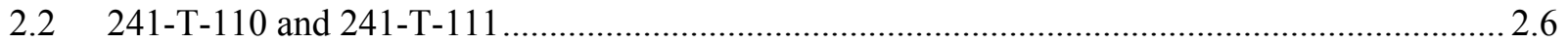

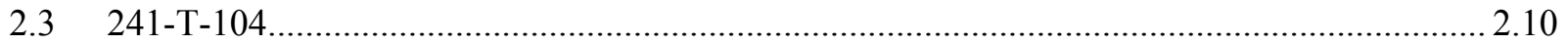

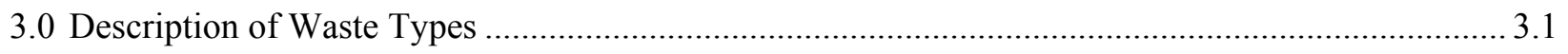

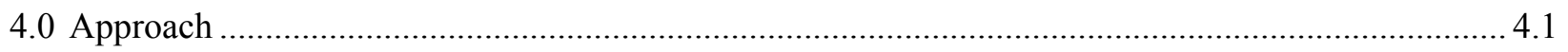

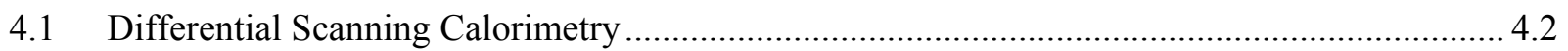

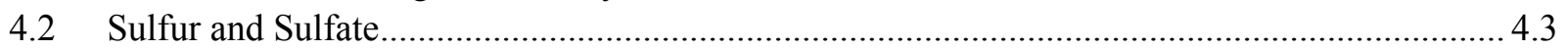

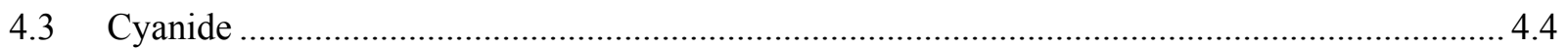

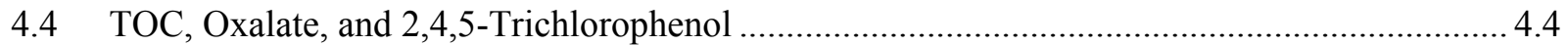

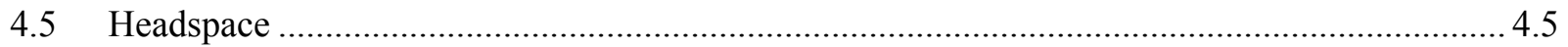

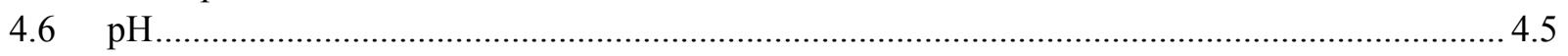

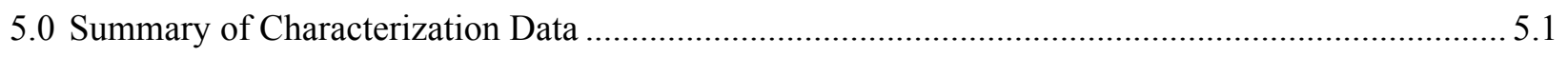

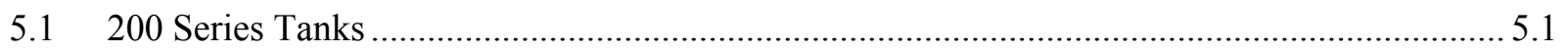

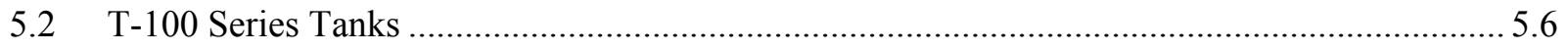

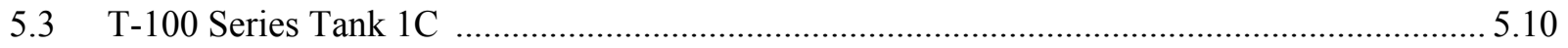

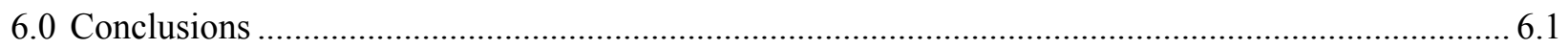

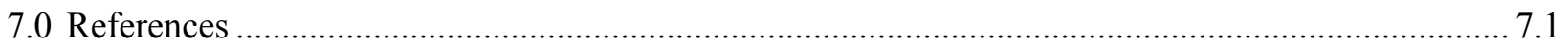

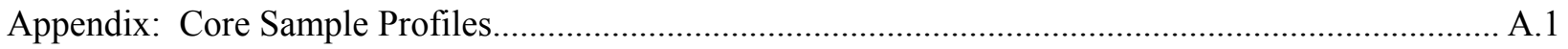




\section{Figures}

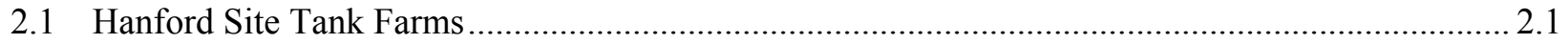

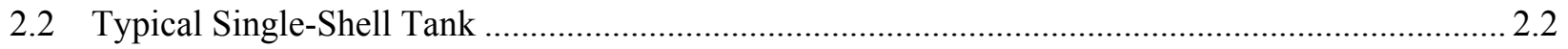

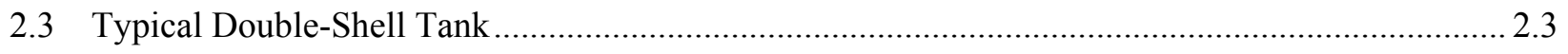

4.1 DSC of Sample from Lower Half of Segment 8, Core 122 ............................................................ 4.2

\section{Tables}

2.1 Waste Volumes in the T- and B-200 Series Tanks as of April 2004 ......................................... 2.5

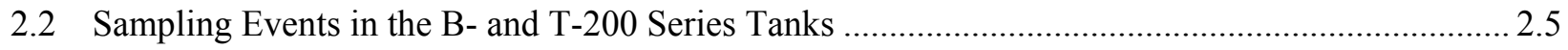

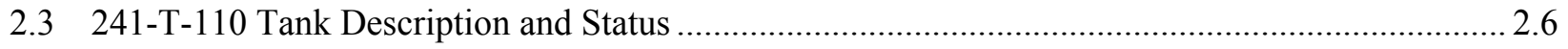

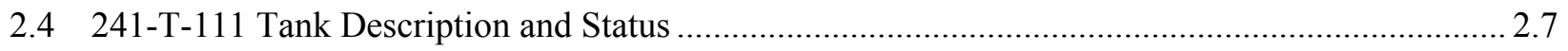

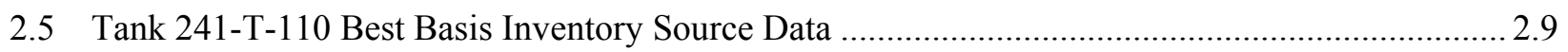

2.6 Tank 241-T-111 Best Basis Inventory Source Data ................................................................. 2.10

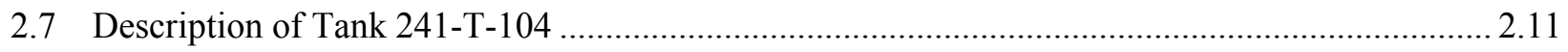

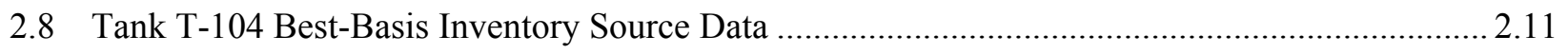

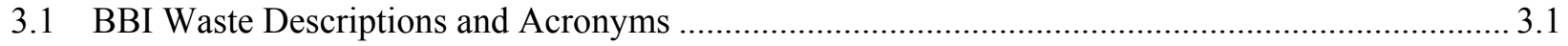

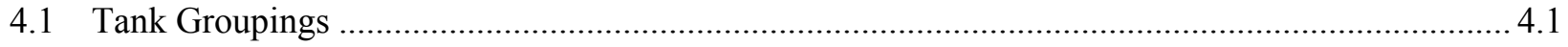

4.2 Analyses Reviewed in Determining Dangerous Waste Characteristics........................................ 4.1

4.3 Threshold Limit Values for Selected Headspace Gases ................................................................ 4.5

5.1 Sulfur and Sulfate Analyses for the B- and T-200 Series Tanks ................................................ 5.2

5.2 Cyanide Analyses for the B- and T-200 Series Tanks ................................................................ 5.3

5.3 TOC and Oxalate Results for the B- and T-200 Series Tanks ....................................................... 5.3

5.4 Mercury Analyses for the B- and T-200 Series Tanks................................................................ 5.4

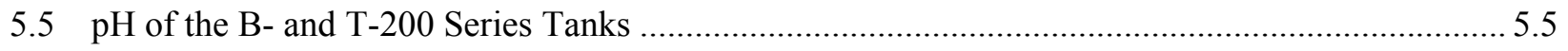

5.6 Headspace Analysis for the B- and T-200 Series Tanks ........................................................... 5.5

5.7 Sulfur and Sulfate Concentrations in Tanks T-110 and T-111 .................................................. 5.7

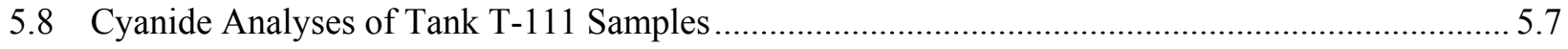

5.9 Headspace Analysis for Tanks T-110 and T-111 ..................................................................... 5.9

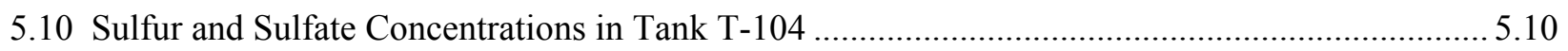

5.11 Cyanide Analyses of Tank T-104 Samples .............................................................................. 5.10

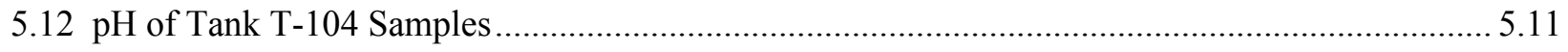

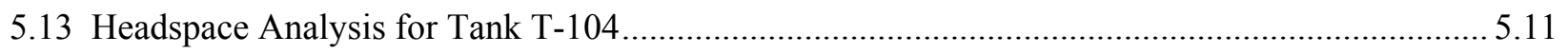




\subsection{Introduction}

Several dangerous characteristics have been assigned to the wastes found in the Hanford underground storage tanks. These characteristics include ignitability, corrosivity, reactivity, and toxicity arising from the presence of 2,4,5-trichlorophenol at levels above the dangerous waste threshold. Existing analytical data from samples taken from the Hanford tanks designated as potentially containing contact-handled $(\mathrm{CH})$ transuranic mixed (TRUM) process wastes, along with process knowledge of the wastes transferred to these tanks, have been reviewed to determine whether the waste codes are applicable to these tank wastes.

\subsection{Background}

Radioactive wastes from defense operations on the Hanford Site were accumulated in 177 underground storage tanks beginning in the 1940s. These wastes came from three different processes for recovering uranium and plutonium from irradiated uranium fuel, three different processes for recovering radionuclides from the waste, from miscellaneous other sources such as laboratories and reactor decontamination solutions, and from production and waste management operations. The acid waste streams were made $\mathrm{pH}$ neutral or alkaline before being transferred into the tanks and formed metal hydroxide sludges. Evaporation of water from these wastes concentrated the wastes to form crystallized salts and salt-rich alkaline solutions.

The U.S. Department of Energy Office of River Protection (DOE-ORP) has responsibility for managing the safe storage, treatment, and disposal of this waste. The tanks contain approximately 53 million gallons of highly radioactive waste and approximately 190 million curies of radioactivity. Current disposition strategies for the majority of these waste includes retrieval of the wastes from the tanks, pretreatment, and vitrification. A Waste Treatment Plant (WTP) is currently being designed and built to perform these operations.

Supplemental technologies are being examined to accelerate the Hanford tank waste cleanup mission and to accomplish waste treatment in a safer and more efficient manner. Methods and equipment to solidify and package the CH-TRUM wastes contained in 11 single-shell tanks (SSTs) are part of the supplemental technologies being evaluated. The resulting packages and wastes must be acceptable for disposal at the Waste Isolation Pilot Plant (WIPP).

\subsection{Transuranic Mixed Wastes (TRUM)}

To date, 11 Hanford waste tanks have been designated as potentially containing CH-TRUM wastes. The CH-TRUM wastes are found in SSTs B-201 through B-204, T-201 through T-204, T-104, T-110, and T-111. Waste from Tank T-110 was initially classified as low-level waste but is being considered a candidate for designation as potentially containing TRU process waste (Gasper et al. 2002). ${ }^{\text {(a) }}$

(a) The proposed TRUM waste packaging system will dry the Tank T-110 waste and increase the concentration of TRU to greater than $100 \mathrm{nCi} / \mathrm{g}$. Thus, the waste in Tank T-110 will meet the minimum TRU concentration requirement for $\mathrm{CH}$ waste disposal at the WIPP. 
A modified dry-retrieval process is proposed to remove the TRUM waste from the Hanford tanks. The sludge is removed from the tank using a vacuum retrieval system. An aqueous stream flowing at approximately 1 to $5 \mathrm{gpm}$ will be added to the retrieved waste in the vacuum line to transfer the diluted waste to a storage vessel. A significant fraction of the liquid in this diluted waste stream must be removed to meet the WIPP disposal criteria. A vacuum drying method (at less than $70^{\circ} \mathrm{C}$ ) has been selected for removing water from this diluted waste. An absorbent may be added to the waste package to prevent the formation of free liquid during handling, transport, and storage of the package.

\subsection{Dangerous Waste Characteristics}

Dangerous waste characteristics, as described in the Dangerous Waste Regulations published by the Washington State Department of Ecology (Ecology 2003), that are assigned to these tanks and are of interest to this study include ignitability, corrosivity, reactivity, and toxicity. Other dangerous waste characteristics are assigned to the TRUM wastes but were not included in this analysis. Characteristics of ignitability (D001), corrosivity (D002), reactivity (D003), and toxicity from 2,4,5-trichlorophenol (D041) associated with the TRUM wastes were considered.

Hanford tank wastes exhibit the characteristics of ignitability if a representative sample of the waste is "capable, under standard temperature and pressure, of causing a fire through friction, absorption of moisture or spontaneous chemical changes and, when ignited, burns so vigorously and persistently that it creates a hazard" or "it is an oxidizer." The other criteria described in the Dangerous Waste Regulations do not apply because the liquids associated with the tank waste are aqueous solutions containing less than 24 percent alcohol by volume, and the tank wastes are not compressed gases.

Wastes that have a $\mathrm{pH}$ less than or equal to 2 or greater than or equal to 12.5 are designated as dangerous wastes due to corrosivity and assigned the dangerous waste number of D002 or WSC2. A designation of WSC2 is assigned when the $\mathrm{pH}$ of the liquid generated from mixing solid or semisolid waste with equal amounts of water is less than or equal to 2 and greater than or equal to 12.5 . If the $\mathrm{pH}$ measured directly on the waste is less than or equal to 2 and greater than or equal to 12.5 , the waste is corrosive and is assigned the dangerous waste designation D002.

Several waste properties must be considered to determine whether it exhibits reactivity. These properties include a representative sample of the waste (1) being normally unstable and readily undergoing a violent change without detonation; (2) reacting violently with water; (3) forming potentially explosive mixtures with water; (4) generating toxic gases, fumes, or vapors at concentrations sufficient to present a danger to human health or the environment when mixed with water; (5) containing cyanide or sulfide which when exposed to $\mathrm{pH}$ conditions between 2 and 12.5 can generate toxic gases, vapors, or fumes at concentrations sufficient to present a danger to human health or the environment; (6) being readily capable of detonation or explosive reaction if it is subjected to a strong initiating source or if heated under confinement; (7) being readily capable of detonation or explosive decomposition or reaction at standard temperature and pressure; and (8) being a forbidden explosive. These properties deal primarily with the energetics of the waste or generation of toxic gases from the waste. 
Toxicity characteristics are based on concentrations of contaminants at or above the dangerous waste thresholds. Only a single contaminant (2,4,5-trichlorophenol) on the toxicity characteristics list is being considered for these tank wastes. The dangerous waste threshold for 2,4,5-trichlorophenol is $400 \mathrm{mg} / \mathrm{L}$. 


\subsection{Tank Waste History Summaries}

Between 1943 and 1964, 149 SSTs were built for storing radioactive wastes generated by the chemical processing of irradiated reactor fuels. The SSTs are located in 12 tank farms in the 200 West and 200 East Areas on the Hanford Site. Figure 2.1 is a reference schematic of these SST farms and the associated six double-shell tank (DST) farms. The capacities of the SSTs range from $208 \mathrm{~m}^{3}(55,000$ gallons) to $3,785 \mathrm{~m}^{3}(1,000,000$ gallons). Carbon steel lines the bottom and sides of the reinforced concrete shell of each tank. The tanks are below grade with at least 6 feet of soil covering them. A sketch of a typical SST is provided in Figure 2.2.

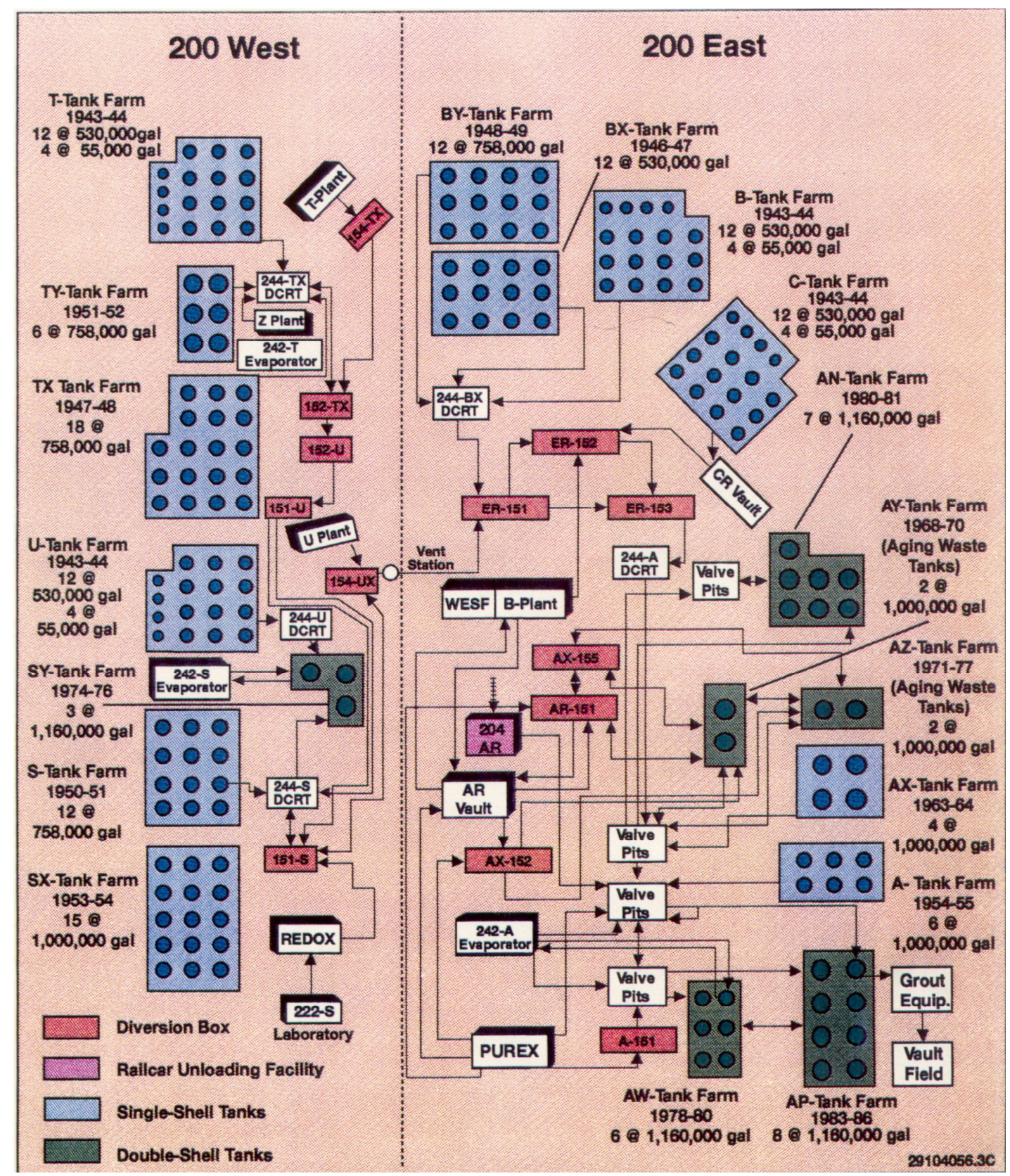

Figure 2.1. Hanford Site Tank Farms 


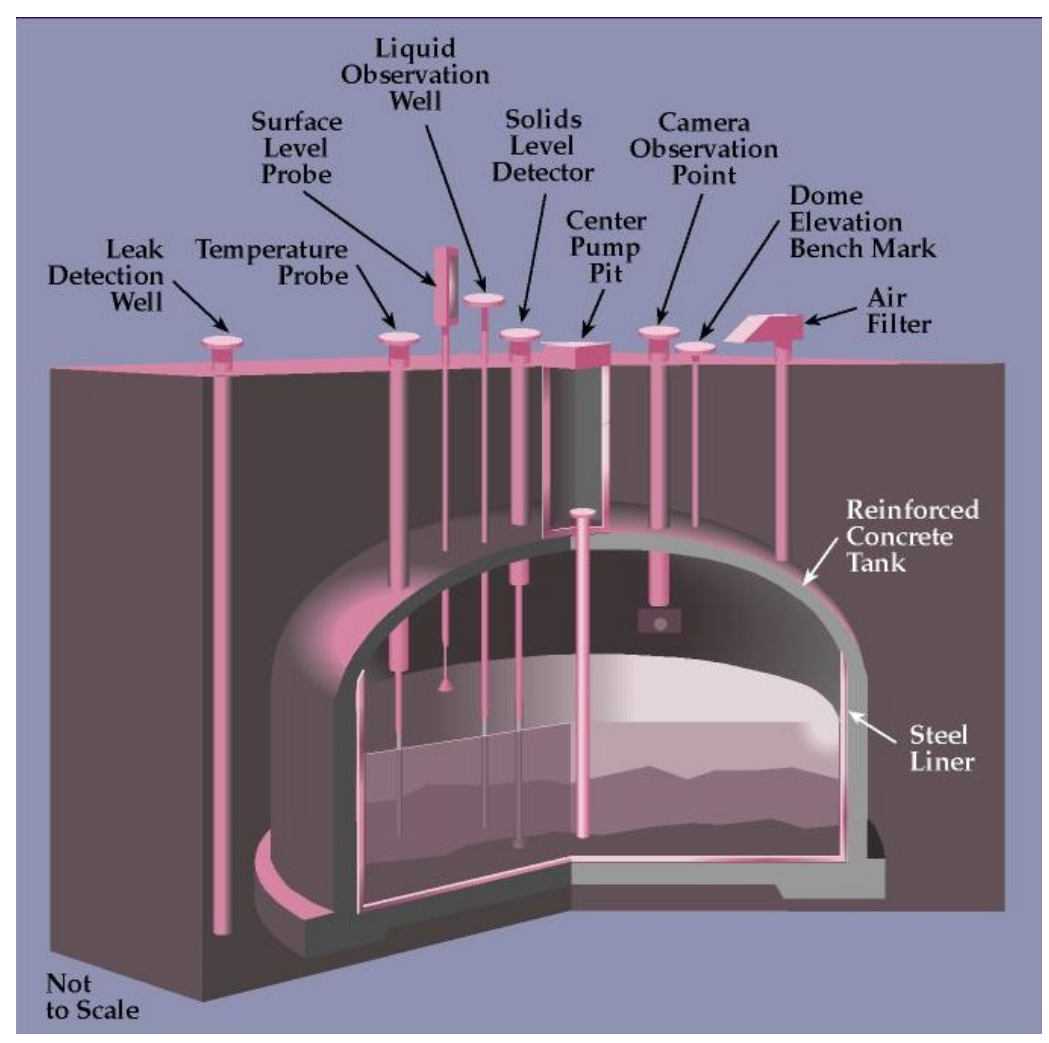

Figure 2.2. Typical Single-Shell Tank

Many of the SSTs were built in "cascades" of three, four, or six tanks. Inlet and overflow lines in these tanks are near the top of the carbon-steel liner. Waste was transferred to the first tank of the cascade and allowed to overflow into the successive tanks of the cascade through the overflow lines.

Twenty-eight DSTs were constructed between 1968 and 1986 to receive liquid radioactive wastes generated by decommissioning and cleanup operations as well as irradiated fuel processing in the 100, 200, 300, and 400 Areas of the Hanford Site. These operations included the transfer of pumpable liquids from the SSTs to the DSTs. Each DST consists of three concentric structures. The outer tank structure is a reinforced concrete tank that is lined with a secondary carbon steel liner that extends along the concrete tank haunch and dome to the inner tank haunch. The inner structure is a free-standing, completely enclosed carbon steel tank located within the secondary liner and separated by an annular space. Leak detection and liquid level detection devices are placed in the annular space. Figure 2.3 is a sketch of a typical DST.

Access to the waste inside the tank is provided by risers that penetrate the tank's dome. The risers vary in diameter from 4 to 42 inches, and the number and size of the risers vary from tank to tank. Both sampling and monitoring of the tanks are performed through these risers, and many of them have been filled with monitoring instrumentation, limiting the locations at which the tank can be sampled.

Several methods have been used at the tank farms to obtain samples of the tank waste. The primary sampling methods include core sampling, grab sampling (also called Bottle-on-a-String), vapor space (headspace) sampling, and auger sampling. 


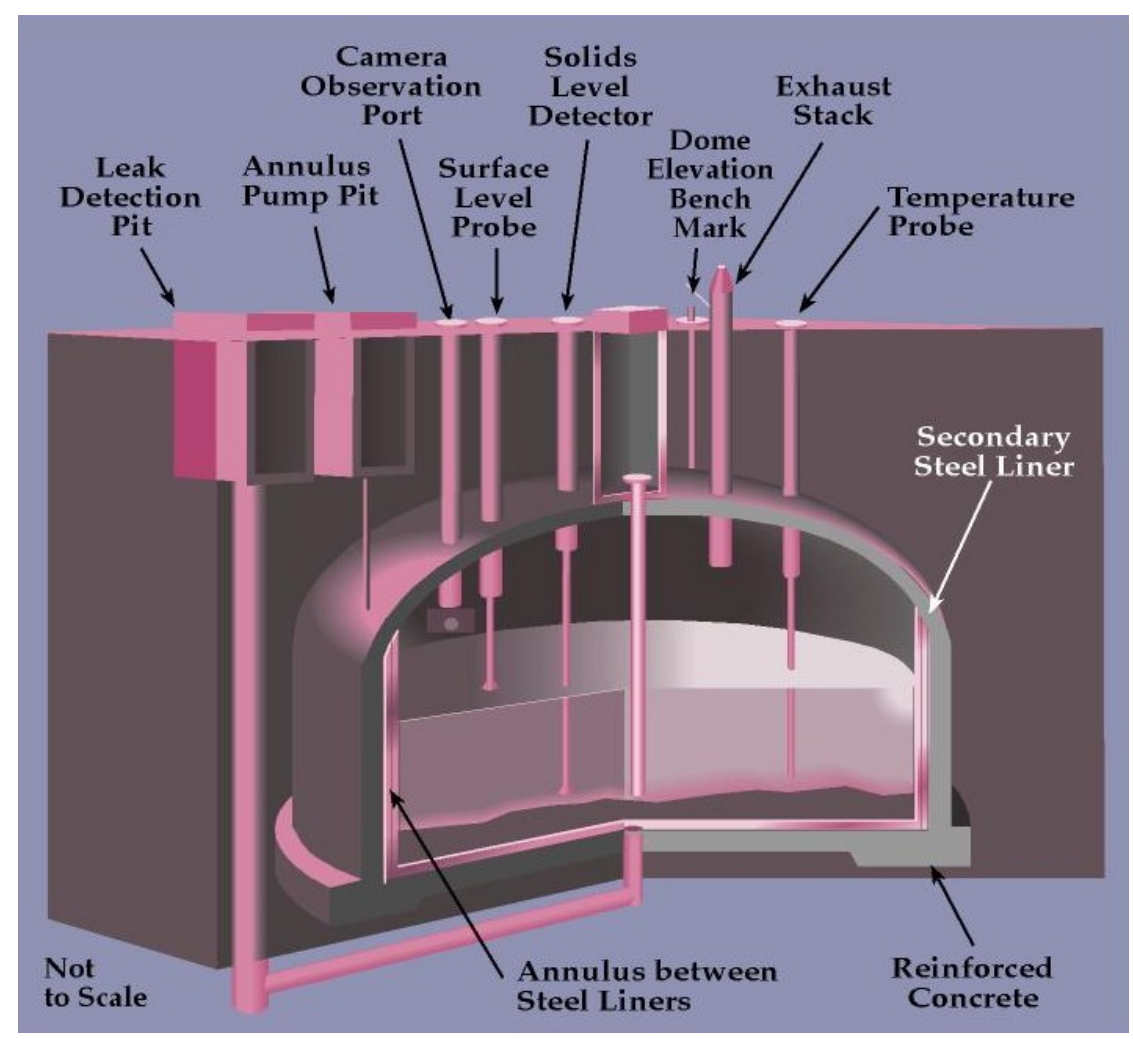

Figure 2.3. Typical Double-Shell Tank

Core samples are solid or liquid samples taken in 19-inch segments throughout the depth of the tank. Core samples are obtained from the tanks using a specially designed core drilling truck and sampling device that is either pushed or rotated through the waste. Core samples provide data on the variation in the composition and properties of the waste as a function of depth in the tank.

Grab samples are liquid or soft slurry samples that are taken from various depths in the liquid waste. A stoppered bottle is lowered to the desired depth in the tank, and the stopper is removed. The bottle fills with the liquid or slurry and is retrieved from the tank.

Vapor space or headspace samples are gas samples obtained at various heights above the surface of the waste in the tank. The vapor is collected in sorbent tubes, SUMMA canisters, or a cryogenic trap. The samples are analyzed in the laboratory by gas chromatography with a mass spectrometer as the detector (GC/MS) or by a gas mass spectrometer. Key analytes are reported along with any other gases that are observed in the samples.

\subsection{1-B-201 through B-204 and 241-T-201 through T-204}

The B-200 and T-200 series tanks are SSTs that were constructed between 1943 and 1944. The B and T tank farms are in the 200 East and 200 West areas, respectively. Each tank farm contains 12100 -series tanks and four 200-series tanks (Brevick et al. 1997). The 200-series tanks have a design capacity of $208 \mathrm{~kL}$ (55 kgal). Some reports list the design capacity of the B 200 -series tanks as $204 \mathrm{~kL}$ (54 kgal) but 
list the same diameter and operating depth. The reported diameter and operating depth at overflow for these tanks is $6.1 \mathrm{~m}(20 \mathrm{ft})$ and $7.49 \mathrm{~m}(24.58 \mathrm{ft})$, respectively. The tanks are passively ventilated. Tanks B-201 and T-201 were piped separately from the other tanks; whereas the B-202, B-203, and B-204 tanks were connected via tie lines, and the T-202, T-203, and T-204 tanks were connected via tie lines. Waste was cascaded through the interconnected tanks. The B-200 and T-200 series tanks received waste from 224-B and 224-T Concentration Buildings, respectively.

The waste in SSTs B-201 through B-204 and T-201 through T-204 was initially produced in the 224$\mathrm{B}$ or 224-T Concentration Building operation as part of the plutonium concentration cycle in the bismuth phosphate process (DuPont 1944). According to the 7/2004 Best-Basis Inventory Derivation Reports, Tanks B-201 and T-201 received lanthanum fluoride finishing waste produced before 1949 (224-1), and the remaining B- and T-200 series tanks received lanthanum fluoride finishing waste produced after 1949 (224-2).

Lanthanum fluoride was added as a carrier precipitate to the plutonium product to remove bismuth and fission products not completely scavenged by the bismuth phosphate in the processing steps that were conducted in the 221-B and 221-T Plants. The 224-B/224-T Concentration Building waste comprised both solid and supernatant fractions. The solids were settled in these tanks (Gasper et al. 2002; Anderson 1990), and the bulk of the fission products settled out with precipitated phosphates and lanthanum fluoride. Fission-product activity of the supernatant fraction of these wastes was low enough $(<0.001 \%$ of the activity in the source material) to permit ground disposal.

Tank B-201 went into service in October 1946 and stopped receiving waste from the 224-B Concentration Building in October 1948. Tanks B-204, B-203 and B-202 were then used from October 1948 through September 1952 to receive waste from the 224-B Concentration Building. The 221-B Plant and 224-B Concentration Building were shut down in September 1952, and the process equipment was flushed between October 1952 and March 1953, with other SSTs also receiving flush solutions from the 221-B Plant. Tanks B-201 through B-204 received flush water periodically from October 1954 through September 1955. A final batch of flush water was added to these tanks in the first half of 1962.

Tank T-201 went into service in November 1946 and stopped receiving waste from the 224-T Concentration Building in May 1949. Tanks T-204, T-203 and T-202 were then used from late May 1949 through May 1952 to receive waste from the 224-T Concentration Building (Johnson 2003). These tanks were declared inactive in 1977. Interim stabilization for all tanks was completed between April 1981 and June 1984, and intrusion prevention was completed between May 1981 and June 1985. The integrity of the T-200 series tanks and Tank B-202 is sound. Tanks B-201, B-203, and B-204 are assumed to be leakers; that is, to have previously leaked waste to the ground.

All of the tanks contain sludge, and Tanks B-203, B-204, and T-201 also contain liquid. Total tank volumes range from 21,000 to 52,000 gallons with the sludge making up most of that volume (21,000 to 51,000 gallons). The liquid volumes were a small fraction of the total volume in the tanks (ranging from 1,000 to 2,000 gallons in the three tanks that had liquid). The volumes for each tank are reported in Table 2.1. 
Table 2.1. Waste Volumes in the T- and B-200 Series Tanks as of April 2004

\begin{tabular}{|l|l|l|l||}
\hline \multirow{2}{*}{ Tank } & \multicolumn{3}{|c|}{$\begin{array}{c}\text { Waste Volume } \\
\text { kL (kgal) }\end{array}$} \\
\cline { 2 - 4 } & \multicolumn{1}{|c|}{ Sludge } & \multicolumn{1}{|c|}{ Supernatant } & \multicolumn{1}{c|}{ Total } \\
\hline B-201 & $115(30$ & 0 & $115(30)$ \\
\hline B-202 & $111(29)$ & 0 & $111(29)$ \\
\hline B-203 & $193(51)$ & $2(1)$ & $195(52)$ \\
\hline B-204 & $189(50)$ & $3(1)$ & $192(51)$ \\
\hline T-201 & $110(29)$ & $9(2)$ & $119(31)$ \\
\hline T-202 & $81(21)$ & 0 & $81(21)$ \\
\hline T-203 & $140(37)$ & 0 & $140(37)$ \\
\hline T-204 & $143(38)$ & 0 & $143(38)$ \\
\hline
\end{tabular}

All samples taken from the B-200 and T-200 series tanks were obtained by core sampling in the push mode. Full cores were obtained for all tanks except B-203 core 115, which omitted the last $\sim 5$ feet. Two additional cores (120 and 122) were obtained from Tank B-203 to provide a complete profile of the waste in this tank (see Figure A.1).

Core profiles are included in the appendix for all tanks except B-201 and B-202. These profiles are single-page diagrams with physical descriptions of the core sampling events for one tank. Core profiles were not available for Tanks B-201 and B-202, but characterization reports provide enough data to determine that full core samples were obtained for both (Heasler et al. 1994; WHC 1995). Eight segments were obtained from cores 26 and 27 from Tank B-201 and seven and eight from cores 24 and 25 , respectively, from Tank B-202. No solids and only $90 \mathrm{~mL}$ of drainable liquid were obtained in the first segment of core 25 . The other core segments were approximately 19 inches in length; thus, approximately 12.7 and 11.1 feet of waste depth were sampled in cores 26 and 27 and 24 and 25, respectively. Because the waste height is approximately $12.77 \mathrm{ft}$ in B-201 and $12.3 \mathrm{ft}$ in B-202, full cores were obtained from both tanks. The data and core identification for each sampling event are listed in Table 2.2.

Table 2.2. Sampling Events in the B- and T-200 Series Tanks

\begin{tabular}{||c|c|c|c||}
\hline \multirow{2}{*}{ Tank } & \multicolumn{3}{|c|}{ Core Samples } \\
\cline { 2 - 4 } & Core Number & Date Sampled & Riser \\
\hline \multirow{2}{*}{ B-201 } & 26 & July 1991 & 2 \\
\cline { 2 - 4 } & 27 & July 1991 & 7 \\
\hline \multirow{2}{*}{ B-202 } & 24 & June 1991 & 2 \\
\cline { 2 - 4 } & 25 & July 1991 & 5 \\
\hline \multirow{3}{*}{ B-203 } & 115 & November 1995 & 2 \\
\cline { 2 - 4 } & 120 & December 1995 & 2 \\
\cline { 2 - 4 } & 122 & December 1995 & 7 \\
\hline \multirow{2}{*}{ B-204 } & 112 & October 1995 & 2 \\
\cline { 2 - 4 } & 114 & October 1995 & 7 \\
\hline T-201 & 192 & April 1997 & 3 \\
\hline T-202 & 191 & April 1997 & 3 \\
\hline T-203 & 190 & April 1997 & 3 \\
\hline T-204 & 188 & March 1997 & 3 \\
\hline
\end{tabular}




\section{$2.2 \quad 241-\mathrm{T}-110$ and $241-\mathrm{T}-111$}

Tanks T-110 and T-111 are 2,006,000-L (530,000-gal) SSTs in the T tank farm (see Figure 2.1). Tank T-110 was designed for non-boiling waste with a maximum fluid temperature of $104^{\circ} \mathrm{C}\left(219^{\circ} \mathrm{F}\right)$. This tank is the first in the line of cascading tanks (T-110, T-111, and T-112), each one a foot lower in elevation than the preceding tank. A description of the tanks plus the tank volumes and sampling events are provided in Tables 2.3 and 2.4.

The wastes received in Tanks T-110 and T-111 are similar to those in the T-200 series tanks except that Tanks $\mathrm{T}-110$ and $\mathrm{T}-111$ also received waste originating from the second plutonium decontamination cycle (2C) from the 221-T Plant (DuPont 1944). Tank T-110 first began receiving second-cycle waste from 221-T Plant in December 1944. Additional second cycle waste was added from 221-T Plant in the first quarter of 1948 until the third quarter of 1956. From the second quarter of 1952 to the first quarter of 1953, the tank also received lanthanum fluoride waste from the 224-T Plutonium Concentration Building. Flush water was added in the second and third quarters of 1956 before the tank was placed on standby.

Table 2.3. 241-T-110 Tank Description and Status

\begin{tabular}{|c|c|}
\hline \multicolumn{2}{|c|}{ Tank Description } \\
\hline Type & Single-shell \\
\hline Constructed & 1943-1944 \\
\hline In-service & $12 / 1944$ \\
\hline Diameter & $22.9 \mathrm{~m}(75 \mathrm{ft})$ \\
\hline Operating Depth & $469.9 \mathrm{~cm}(185 \mathrm{in})$ \\
\hline Design Capacity & $2006 \mathrm{~kL}(530 \mathrm{kgal})$ \\
\hline Bottom shape & dish \\
\hline Ventilation & Passive \\
\hline \multicolumn{2}{|c|}{ Tank Status (as of $4 / 1 / 2004)$} \\
\hline Total Waste Volume & $1400 \mathrm{~kL}(370 \mathrm{kgal})$ \\
\hline Supernatant Volume & $3 \mathrm{~kL}(1 \mathrm{kgal})$ \\
\hline Sludge Volume & $1397 \mathrm{~kL}(369 \mathrm{kgal})$ \\
\hline Surface Level (4/1/2004) & $370.8 \mathrm{~cm}$ (146.0 inches) \\
\hline PCSACS Surface Level (8/16/2004) & $370.7 \mathrm{~cm}$ (145.9 inches) \\
\hline Integrity & Sound \\
\hline Waste Group Designation & $\mathrm{B}$ \\
\hline \multicolumn{2}{|c|}{ Sampling Dates } \\
\hline Core Samples & $1 / 29 / 1996-2 / 10 / 1996$ \\
\hline Grab Samples & $1 / 8 / 1997-1 / 8 / 1997$ \\
\hline Vapor Samples & $8 / 31 / 1995$ \\
\hline \multicolumn{2}{|c|}{ Service Status } \\
\hline Declared Inactive & 1976 \\
\hline Interim Stabilization & January 2000 \\
\hline
\end{tabular}


Table 2.4. 241-T-111 Tank Description and Status

\begin{tabular}{|c|c|}
\hline \multicolumn{2}{|c|}{ Tank Description } \\
\hline Type & Single-shell \\
\hline Constructed & $1943-1944$ \\
\hline In-service & $10 / 1945$ \\
\hline Diameter & $22.9 \mathrm{~m}(75 \mathrm{ft})$ \\
\hline Operating Depth & $469.9 \mathrm{~cm}(185 \mathrm{in})$ \\
\hline Design Capacity & $2006 \mathrm{~kL}(530 \mathrm{kgal})$ \\
\hline Bottom shape & dish \\
\hline Ventilation & Passive \\
\hline \multicolumn{2}{|c|}{ Tank Status (as of $4 / 1 / 2004)$} \\
\hline Total Waste Volume & $1691 \mathrm{~kL}(447 \mathrm{kgal})$ \\
\hline Sludge Volume & $1691 \mathrm{~kL}(447 \mathrm{kgal})$ \\
\hline Surface Level (4/1/2004) & $432.3 \mathrm{~cm}$ (170.2 inches) \\
\hline PCSACS Surface Level (8/16/2004) & $432.6 \mathrm{~cm}$ (170.3 inches) \\
\hline Integrity & Assumed leaker \\
\hline Waste Group Designation & $\mathrm{B}$ \\
\hline \multicolumn{2}{|c|}{ Sampling Dates } \\
\hline \multirow[t]{2}{*}{ Core Samples } & $10 / 22 / 1991-10 / 25 / 1991$ \\
\hline & $11 / 5 / 1991-11 / 7 / 1991$ \\
\hline Vapor Samples & $1 / 20 / 1995$ \\
\hline \multicolumn{2}{|c|}{ Service Status } \\
\hline Declared Inactive & 1976 \\
\hline Interim Stabilization & February 1995 \\
\hline Intrusion Prevention & \\
\hline
\end{tabular}

The tank was inactive and full until the second quarter of 1974, when supernatant waste was sent to Tank S-110. Supernatant waste was sent to T-101 in the first and second quarters of 1976 and to TX-118 in the third quarter of 1978. The last transfer from Tank T-110 prior to core sampling of the tank was saltwell pumping of liquids to Tank AN-103 in the fourth quarter of 1983. Saltwell pumping began again in May 1997, and the pump remains within the waste. As of August 31, 1997, 63.2 kL of supernatant liquid had been pumped from the tank, including the sluice water and any liquids that may have intruded into the tank from outside via pump pits.

Tank T-111 was brought into service during the fourth quarter of 1945 with a cascade of second cycle decontamination (2C) waste from Tank T-110 (Agnew et al. 1997b). The tank was filled with 2C waste, and the waste was cascaded to Tank T-112. Cascading continued until the third quarter of 1946, when Tank T-112 was filled. During the third and fourth quarters of 1947, nearly all of the supernatant of Tank T-111 was transferred to crib T-006. The cascading of $2 \mathrm{C}$ waste resumed in the first quarter of 1948. When the entire cascade became full, waste from T-112 was transferred to a crib. This cycle continued until the fourth quarter of 1952. From 1952 to 1956, Tank T-111 was used to cascade $2 \mathrm{C}$ waste from 221-T Plant and lanthanum fluoride waste (224) from the lanthanum fluoride finishing process in the 224$\mathrm{T}$ plutonium concentration building to Tank T-112, which discharged to a crib. In 1995, supernatant waste was transferred from the tank to crib T-005. 
Tank T-111 contents remained unchanged until the second quarter of 1974 . From 1974 to 1976 , 63,000 gallons of supernatant were transferred to Tanks S-110, T-101, T-109, and TX-109. Tank T-111 was declared inactive after these transfers were complete in 1976. Saltwell liquid was pumped from the tank in support of tank stabilization efforts in the fourth quarter of 1990, the fourth quarter of 1994, and the first quarter of 1995. The tank is currently characterized as an assumed leaker (Hanlon 2002).

The two cascade tanks (T-111 and T-112) from Tank T-110, along with Tank T-110, have been sampled and analyzed, and the resulting data contribute significantly to the understanding of Tank T-110. Bismuth phosphate second-cycle (2C) waste was the principal waste type added to T-110. For a short period of time, lanthanum fluoride finishing (224) waste was added to the tank and cascaded over into Tanks T-111 and T-112. Predicting the relative proportions of $2 \mathrm{C}$ waste solids and 224 waste solids to the overall tank waste inventory is difficult.

Due to the limited analytical information on the solids from the 1996 samples, estimates of tank contents were made based on data for Tanks T-111 and T-112, which indicate a higher contribution of lanthanum fluoride finishing (224) waste from Tank T-110, with a $2 \mathrm{C} / 224$ waste ratio of 80/20 or 75/25. Other tanks with sample data for the lanthanum fluoride finishing waste type include the T-200 and B-200 series tanks. Tanks B-110, B-111, and B-112 also contain a waste layer that is representative of 2C waste.

All appropriate data quality objectives (DQO) and waste issues have been addressed for Tank T-110 and accepted by the Project Hanford Management Contract Tank Waste Remediation System Program. No additional sampling and analyses are needed to satisfy current safety issue requirements for this tank. Tank T-110 was core-sampled through two risers between January 29 and February 7, 1996. Core 180 was taken from riser 6 on February 6 and 7, 1996, and core 181 was taken from riser 2 on January 29 and $30,1996$.

All applicable DQOs and waste issues have been addressed for Tank T-111, and no additional sampling and analyses are necessary to satisfy current safety issue requirements. Tank T-111 was push-mode core-sampled through three risers between October 22 and November 7, 1991. Core 31 was taken from riser 6 on October 22, 1991, and core 32 was taken from riser 2 on October 24 and 25, 1991. Core 33 was taken from riser 3 between November 5 and 7, 1991.

A hydrostatic fluid of normal paraffin hydrocarbons (NPH), similar to kerosene, was used in establishing a head balance while taking push-mode cores. Objections involving sample degradation and contamination were raised regarding the use of this fluid, and the practice has since been discontinued. For cores 31 and 33, nearly full recovery was achieved in every case.

The casks were transported to the 222-S Laboratory for characterization. Some of the physical tests, organic analyses, and uranium and plutonium isotopic analyses were performed at the Radiochemical Processing Laboratory (RPL) operated by Pacific Northwest National Laboratory (PNNL).

For cores 31 and 33, sample recovery was excellent; overall recoveries were in excess of 80 percent. Segment recoveries were based on the maximum recoverable volume for the segment regardless of solid/liquid ratio. The core recoveries reported in the data package were determined based on a visual inspection of the sample length and apparent volume at the time the samples were extruded. Although 
samples for core 32 were taken from riser 2, the materials obtained at all levels appeared to be particulate suspended in an aqueous solution, with slight traces of NPH contamination observed in a few samples. These samples did not correspond to the observed conditions in the tank and were considered nonrepresentative. The results of the core 32 sampling exercise were attributed to sampler failure. Because no acceptable samples were acquired, no assays were performed on core 32 and no results were reported. The analytical data were reported in McKinney et al. (1993).

Grab samples were obtained from Tank T-111 on March 5, 1994. ${ }^{\text {(a) }}$ Three 100-mL supernatant samples were retrieved from riser 13 (saltwell screen) in accordance with waste compatibility program requirements (WHC 1994). The compatibility samples were taken for emergency pumping of T-111 to SY-102. The samples were sent to the 222-S laboratory for analysis on March 25, 1994. Quality control (QC) analyses were not conducted for the three grab samples.

Vapor sampling of Tank T-111 to support the Health and Safety DQO (Osborne and Buckley 1995) was performed on January 20, 1995 using the vapor sampling system (VSS). Air from the T-111 headspace was withdrawn via a $6.1-\mathrm{m}(20-\mathrm{ft})$ long heated sampling probe mounted in riser 3 and transferred through heated tubing to the VSS sampling manifold. All heated zones of the VSS were maintained at approximately $50^{\circ} \mathrm{C}\left(120^{\circ} \mathrm{F}\right)$ (Huckaby and Bratzel 1995). Samples were collected in SUMMA $^{\mathrm{TM}}$ canisters or various types of sorbent traps. Samples collected in a triple sorbent trap device were analyzed by Oak Ridge National Laboratory (ORNL) for organic vapors. PNNL analyzed both SUMMA and sorbent trap devices for inorganic and organic vapors. Because of differences in documenting quality assurance measures between ORNL and PNNL, PNNL SUMMA sample results should be considered the primary organic vapor data for T-111.

The Best Basis Inventory (BBI) for T-111 and T-110 incorporates waste-type templates that correlate with the waste types in the tank. Templates are based on sampling data from tanks that contain the same waste type as Tanks T-111 and T-110, supplemented with Hanford Defined Waste (HDW) model (Agnew et al. 1997a) data and contribute significantly to the understanding of the concentrations of certain constituents in these tanks. The BBI source data are provided in Tables 2.5 and 2.6. The sludge waste phase includes both solids and interstitial liquid.

Table 2.5. Tank 241-T-110 Best Basis Inventory Source Data

\begin{tabular}{|l|c|c|}
\hline \multicolumn{1}{|c|}{ Waste Phase } & Waste Type & Associated Volume \\
\hline Supernatant & $2 \mathrm{C} 1$ & $3 \mathrm{~kL}(1 \mathrm{kgal})$ \\
\hline \multirow{2}{*}{ Sludge } & $224-2$ & $37 \mathrm{~kL}(10 \mathrm{kgal})$ \\
\cline { 2 - 3 } & $2 \mathrm{C}$ & $1,360 \mathrm{~kL}(359 \mathrm{kgal})$ \\
\hline Total tank & $1,400 \mathrm{~kL}(370 \mathrm{kgal})$ \\
\hline
\end{tabular}

(a) Sutey MJ. April 8, 1994. "Waste Compatibility Assessment of Tank 241-SY-102 with Tank 241-T-111 via 244-TX-DCRT." Letter 7CF30-94-011 to JH Wicks, Westinghouse Hanford Company, Richland, WA. 
Table 2.6. Tank 241-T-111 Best Basis Inventory Source Data

\begin{tabular}{|l|c|c||}
\hline \multicolumn{1}{|c|}{ Waste Phase } & Waste Type & $\begin{array}{c}\text { Associated } \\
\text { Volume }\end{array}$ \\
\hline \multirow{2}{*}{ Sludge } & $224-2$ & $904 \mathrm{~kL}(239 \mathrm{kgal})$ \\
\cline { 2 - 3 } & $2 \mathrm{C}$ & $787 \mathrm{~kL}(208 \mathrm{kgal})$ \\
\hline Total tank & $1,691 \mathrm{~kL}(447 \mathrm{kgal})$ \\
\hline
\end{tabular}

\section{$2.3 \quad 241-\mathrm{T}-104$}

Tank T-104 was constructed during 1943 and 1944. It is a 2,006,000-L (530,000-gal) SST in the $\mathrm{T}$ tank farm (see Figure 2.1). Tank T-104 was designed for non-boiling waste with a maximum fluid temperature of $104^{\circ} \mathrm{C}\left(219^{\circ} \mathrm{F}\right)$. This tank is the first in the line of cascading tanks $(\mathrm{T}-104, \mathrm{~T}-105$, and $\mathrm{T}$-106), each $1 \mathrm{ft}$ lower in elevation than the preceding tank. A description of the tank, tank volumes, and sampling events is provided in Table 2.7.

Tank T-104 was used to periodically receive first decontamination cycle (1C) waste and coating removal waste (CW) from the 221-T Bismuth Phosphate Plant from March 11, 1946 through October 19, 1956. No other waste types were received and stored in Tank T-104. During storage in the SSTs, the $1 \mathrm{C} / \mathrm{CW}$ waste precipitated solids that contained primarily aluminum, bismuth, plutonium, americium, uranium, sodium, phosphate, sulfate, and metals. The $1 \mathrm{C} / \mathrm{CW}$ supernatant contained primarily aluminum, sodium, nitrate, and cesium-137. As a result, T-104 contained settled $1 \mathrm{C} / \mathrm{CW}$ solids (i.e., bismuth and plutonium precipitate) and $1 \mathrm{C} / \mathrm{CW}$ supernatant. The $1 \mathrm{C} / \mathrm{CW}$ supernatant was removed from Tank $\mathrm{T}-104$ and processed in the 242-T Evaporator (April through July 1951) or disposed in the east section of trench 216-T-14 (January 14, 1954). The interstitial liquid was removed from the 1C/CW sludge present in Tank T-104 and transferred to other underground storage tanks in two campaigns conducted February 1976 to August 1977 and March 24, 1996 to May 30, 1999 (Johnson 2003).

The BBI for Tank T-104 incorporates waste-type templates that correlate with the waste types listed in Table 2.8. Templates are based on sampling data from tanks that contain the same waste type as Tank T-104, supplemented with HDW model data (Agnew et al. 1997a), and contribute significantly to the understanding of the concentrations of certain constituents in the T-104 waste. Tank T-104 contains $1,199 \mathrm{~kL}(317 \mathrm{kgal})$ of waste and one defined waste phase - sludge (waste type 1C) according to the current BBI. Other tanks with a $1 \mathrm{C}$ inventory include B, BX, C, T, TX, and U farm tanks.

The VSS was used to collect representative samples of the air, gases, and vapors from the headspace of Tank T-104 with sorbent trap and SUMMA ${ }^{\text {TM }}$ canisters on February 7, 1996. Sampling devices and controls provided for this job included 11 sorbent trains for selected inorganic analytes (eight sample trains and three field blanks) and five SUMMA canister for permanent gases and total non-methane hydrocarbons (three sample and two ambient canisters).

Two core samples were collected from Tank T-104. Core 45 was obtained from riser 3 on August 20 and 26, 1992, and core 46 was obtained from riser 6 on August 27 and 28, 1992. Core sampling was used because of the phase (solid versus liquid) and depth of the waste and the expectation that a full vertical profile of the waste would be obtained. NPH was used as the hydrostatic head fluid. 
Table 2.7. Description of Tank 241-T-104

\begin{tabular}{|c|c|}
\hline \multicolumn{2}{|c|}{ Tank Description } \\
\hline Type & Single-shell \\
\hline Constructed & $1943-1944$ \\
\hline In-service & $3 / 1946$ \\
\hline Diameter & $22.9 \mathrm{~m}(75 \mathrm{ft})$ \\
\hline Operating Depth & $469.9 \mathrm{~cm}(185 \mathrm{in})$ \\
\hline Design Capacity & $2006 \mathrm{~kL}(530 \mathrm{kgal})$ \\
\hline Bottom shape & dish \\
\hline Ventilation & Passive \\
\hline \multicolumn{2}{|c|}{ Tank Status (as of $1 / 1 / 2001)$} \\
\hline Total Waste Volume & $1199 \mathrm{~kL}(317 \mathrm{kgal})$ \\
\hline Supernatant Volume & $\mathrm{NA}$ \\
\hline Retained Gas Volume & $\mathrm{NA}$ \\
\hline Retained Gas - Sludge Volume & NA \\
\hline Retained Gas - Salt Cake Volume & $\mathrm{NA}$ \\
\hline Salt Cake Liquid Volume & NA \\
\hline Salt Cake Solid Volume & $\mathrm{NA}$ \\
\hline Sludge Volume & $1199 \mathrm{~kL}(317 \mathrm{kgal})$ \\
\hline Surface Level (10/3/2000) & $311.4 \mathrm{~cm}$ (122.6 in.) \\
\hline PCSACS Surface Level (3/1/2004) & $311.4 \mathrm{~cm}(122.6$ in.) \\
\hline Integrity & Sound \\
\hline Waste Group Designation & $\mathrm{C}$ \\
\hline \multicolumn{2}{|c|}{ Sampling Dates } \\
\hline \multirow[t]{2}{*}{ Core Samples } & $8 / 20 / 1992-8 / 26 / 2002$ \\
\hline & $8 / 27 / 1992-8 / 28 / 1992$ \\
\hline Vapor Samples & $2 / 7 / 1996$ \\
\hline \multicolumn{2}{|c|}{ Service Status } \\
\hline Declared Inactive & 1977 \\
\hline Interim Stabilization & November 1999 \\
\hline Intrusion Prevention & None \\
\hline
\end{tabular}

Table 2.8. Tank T-104 Best-Basis Inventory Source Data

\begin{tabular}{|c|c|c|c|}
\hline Waste Phase & Waste Type & Applicable Concentration Data & Associated Volume \\
\hline \multirow{3}{*}{ Sludge $\mathrm{e}^{(\mathrm{a})}$} & \multirow{3}{*}{$1 \mathrm{C}$} & $\begin{array}{l}1992 \text { core composite solids mean } \\
\text { concentrations (S/T104/005) }\end{array}$ & \multirow{3}{*}{$\begin{array}{c}1,199 \mathrm{~kL} \\
(317 \mathrm{kgal})\end{array}$} \\
\hline & & 1C sludge template (TS/U204/006) & \\
\hline & & T-104 sludge PCBs (P/T104/005) & \\
\hline \multicolumn{3}{|l|}{ Total Tank } & $1,199 \mathrm{~kL}(317 \mathrm{kgal})$ \\
\hline
\end{tabular}




\subsection{Description of Waste Types}

The waste types added to the tanks containing the CH-TRUM waste include lanthanum fluoride finishing waste before and after 1949, and first- and second-cycle waste from the bismuth phosphate process. The waste descriptions and acronyms used in the BBI are provided in Table 3.1.

Table 3.1. BBI Waste Descriptions and Acronyms

\begin{tabular}{||l|l||}
\hline \multicolumn{2}{|c|}{ Acronym } \\
\hline \multicolumn{1}{|c|}{ CH-TRUM } \\
\hline $1 \mathrm{C}$ & $1^{\text {st }}$ cycle decontamination waste from the $\mathrm{BiPO}_{4}$ process \\
\hline $2 \mathrm{C} 1$ & $2^{\text {nd }}$ cycle waste from the $\mathrm{BiPO}_{4}$ process $(1944$ to 1951$)$ \\
\hline $2 \mathrm{C}$ & $2^{\text {nd }}$ cycle waste from the $\mathrm{BiPO}_{4}$ process \\
\hline $224-1$ & $\mathrm{LaF}_{3}$ finishing waste (pre 1949) \\
\hline $224-2$ & $\mathrm{LaF}_{3}$ finishing waste (post 1949) \\
\hline
\end{tabular}




\subsection{Approach}

The 11 selected tanks were categorized into three groupings. These groupings and the tanks associated with them are provided in Table 4.1. Existing analytical data from tank waste samples were reviewed and combined with data from similar wastes along with process knowledge of the wastes transferred into the tanks to determine whether selected dangerous waste codes are applicable.

Table 4.1. Tank Groupings

\begin{tabular}{||c|c|c|l||}
\hline \multicolumn{1}{|c|}{ Group } & Tanks & Tank Type & \multicolumn{1}{|c||}{ Waste Types } \\
\hline B- and T-200 Series Tanks & $241-\mathrm{B}-201$ & Single-shell & LaF Finishing \\
& $241-\mathrm{B}-202$ & & (both pre- and post-1948) \\
& $241-\mathrm{B}-203$ & & \\
& $241-\mathrm{B}-204$ & & \\
& $241-\mathrm{T}-201$ & & \\
& $241-\mathrm{T}-202$ & & \\
& $241-\mathrm{T}-203$ & & \\
& $241-\mathrm{T}-204$ & & \\
\hline T-100 Series Tanks 2C/224 & $241-\mathrm{T}-110$ & Single-shell & LaF $_{3}$ finishing $($ post-1948) \\
& $241-\mathrm{T}-111$ & & ${\text { Second-cycle } \mathrm{BiPO}_{4}}$ \\
\hline T-100 Series Tanks - 1C & $241-\mathrm{T}-104$ & Single-shell & First-cycle $\mathrm{BiPO}_{4}$ \\
\hline
\end{tabular}

The analytical data reviewed included DSC results; concentrations of sulfur, sulfate, cyanide, 2,4,5trichlorophenol, TOC, and oxalate; the composition of headspace (vapor space); and $\mathrm{pH}$. The dangerous waste codes to which each analysis was applied are provided in Table 4.2. This section discusses the sample analysis methods and the data review approach. Section 5 compares the analytical data with the dangerous waste characteristics.

Table 4.2. Analyses Reviewed in Determining Dangerous Waste Characteristics

\begin{tabular}{||l|c|c||}
\hline Analysis & Waste Code & Characteristic \\
\hline DSC & D001/D003 & Ignitability and Reactivity \\
\hline Sulfur & D003 & Reactivity \\
\hline Sulfate & D003 & Reactivity \\
\hline Cyanide & D003 & Toxivity \\
\hline $2,4,5$-trichlorophenol & D041 & Toxicity \\
\hline TOC & D041 & Toxicity \\
\hline Oxalate & D041 & Ignitability and Reactivity \\
\hline Headspace & D001/D003 & Corrosivity \\
\hline pH & D002 & \\
\hline
\end{tabular}




\subsection{Differential Scanning Calorimetry}

DSC results have been used to determine the energetics of the tank wastes as a function of temperature. DSC plots are graphs of the differential heating rate versus temperature. An example scan is provided in Figure 4.1.

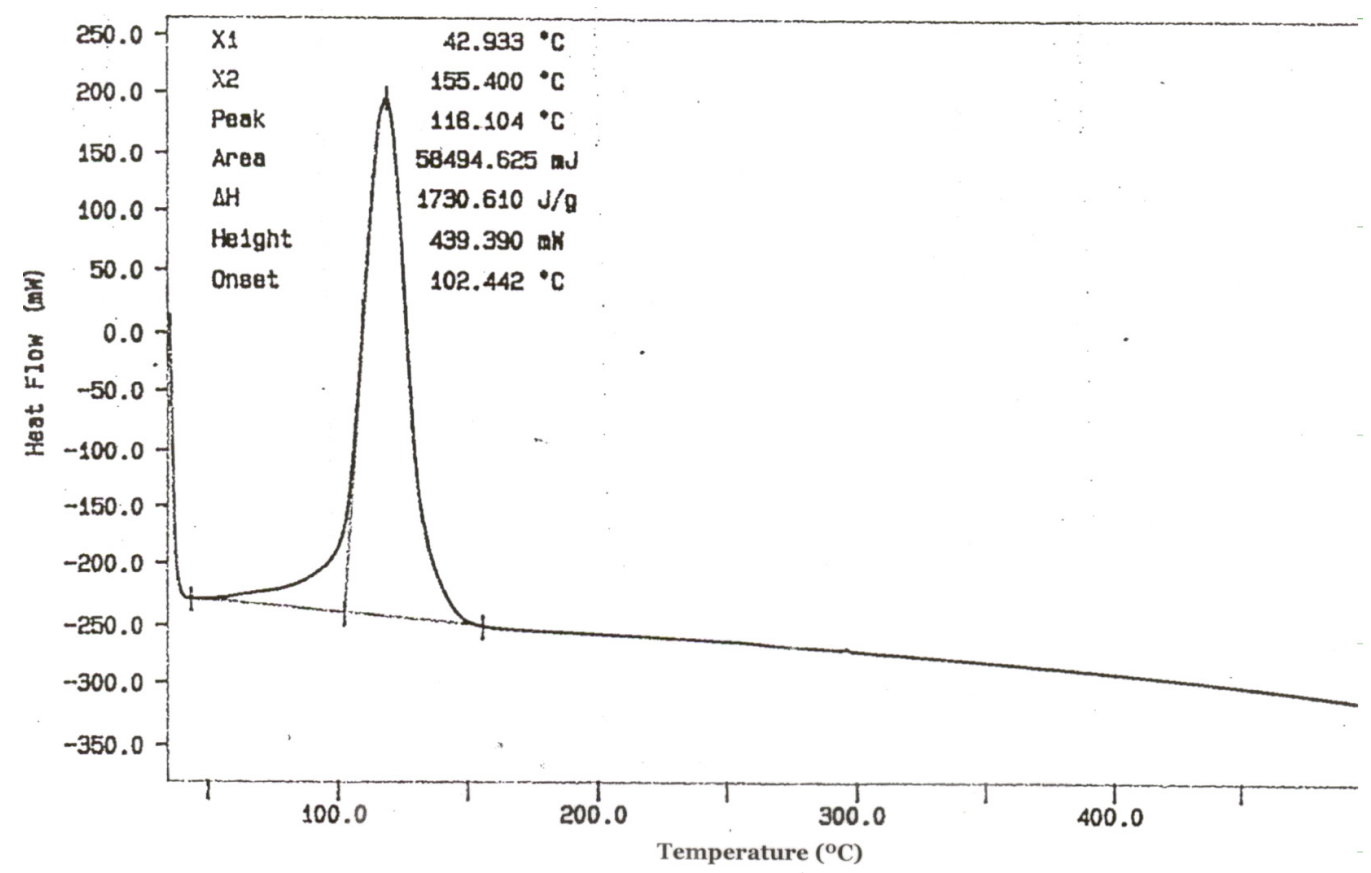

Figure 4.1. DSC of Sample from Lower Half of Segment 8, Core 122 (Tank 241-B-203). Exotherms appear below the baseline and endotherms are above the baseline.

DSC measures the differential power (heat input) necessary to keep a sample and an inert reference substance isothermal as temperature is increased linearly. The data generated by DSC is used to determine heats of reaction, reaction rates, phase transitions, and thermal stabilities. In a DSC scan several transitions may be observed, each indicating at least one separate reaction or phase transition. The area under the peak of each transition is directly proportional to the heat evolved (exothermic) or absorbed (endothermic) by the reaction or phase transition, and the height of the curve is directly proportional to the rate of reaction. In DSC sharp exothermic transitions with large heats of reaction are indicative of unstable materials with vigorous or violent reactions such as explosions or detonations.

The results of the DSC were reviewed for each tank to determine whether any exothermic behavior was observed. If exothermic behavior was observed, the DSC scans were reviewed and the shape and energy of these transitions were determined. If no exothermic behavior was observed or the exothermic transitions were broad with low heats of reactions, the waste was considered stable, with no violent reactions if heated. These results also indicate that the waste is not capable of spontaneous chemical changes that could result in a fire at standard temperature and pressure. If significant endothermic transitions had to occur before the exothermic reaction could occur, the waste could also be considered stable at standard temperature and pressure. 
Because all of these tank wastes contain interstitial liquid as aqueous salt solutions, the DSC results obtained on the samples also indicate the reactivity and ignitability of the waste in the presence of water or upon absorption of moisture.

\subsection{Sulfur and Sulfate}

The major sources of sulfur-containing compounds in Hanford tank wastes are sulfuric acid $\left(\mathrm{H}_{2} \mathrm{SO}_{4}\right)$, ferrous sulfamate $\left[\mathrm{Fe}\left(\mathrm{SO}_{3} \mathrm{NH}_{2}\right)_{2}\right]$, sodium sulfate $\left(\mathrm{Na}_{2} \mathrm{SO}_{4}\right)$, and sulfamic acid $\left(\mathrm{HSO}_{3} \mathrm{NH}_{2}\right)$. Sulfate ions (in the form of sulfuric acid) were used in the bismuth phosphate process to form uranyl sulfate $\left[\mathrm{UO}_{2}\left(\mathrm{SO}_{4}\right)_{2}{ }^{2-}\right]$ so that it did not coprecipitate with the plutonium. Uranyl sulfate and most of the sulfate ions from the bismuth phosphate process were present in the metal waste stream that was not discharged to any of the SSTs containing the candidate CH TRU mixed waste. Some sulfate ions would have been carried forward with the plutonium in the bismuth phosphate process and been present in the $1 \mathrm{C}$ waste stream. Both ferrous sulfamate and sulfamic acid were used to reduce Pu at oxidation states between IV and VI to the $\mathrm{Pu}(\mathrm{III})$ oxidation state in the bismuth phosphate process, and sulfate ions were present in both the $1 \mathrm{C}$ and $2 \mathrm{C}$ wastes streams. Both sulfuric acid $\left(\mathrm{H}_{2} \mathrm{SO}_{4}\right)$ and ammonium sulfate $\left[\left(\mathrm{NH}_{4}\right)_{2} \mathrm{SO}_{4}\right]$ were used in the 231-Z plutonium finishing process, and plutonium-containing waste from this process was recycled to the 224-B and 224-T Concentration Buildings for plutonium recovery. Sulfamic acid was used prior to oxalate precipitation of $\mathrm{Pu}$, and ferrous sulfamate was used in the REDOX and PUREX flow sheets to form the inextractable $\mathrm{Pu}\left(\mathrm{NO}_{3}\right)_{3}$ during the solvent extraction process. Sodium sulfate was used in B Plant (1968-1984) to precipitate strontium and separate metal impurities during processes conducted to prepare the strontium for encapsulation. Under tank conditions these sulfur compounds would tend to form sulfates. Tank waste conditions are mildly oxidizing from the abundant nitrate, which also precludes formation of sulfide from sulfate. Therefore, a source of sulfide is not evident in these tanks. If sulfide were present under the $\mathrm{pH}$ conditions in the tanks, the predominant form of the sulfide species would be $\mathrm{HS}^{-}$, and the release of $\mathrm{H}_{2} \mathrm{~S}$ would be well below toxic concentrations. Detailed information about sulfate chemistry in the Hanford tank wastes is provided in a letter report prepared by Bruce McNamara for CH2M Hill Hanford Group, Inc. ${ }^{(a)}$

Sulfide concentrations in the waste were estimated by the ratio of sulfur to sulfate because no sulfide determination was made on the tank waste samples. Sulfur was determined directly by Inductively Coupled Plasma (ICP) mass spectroscopy on liquid samples from some tanks and on both fusions and acid digestions of solid samples from some tanks. Sulfate was measured by ion chromatography (IC) on liquid samples from the tank as well as water digestions of the solid samples from the tanks. If all of the sulfur were present as sulfate, the mass ratio of sulfate to sulfur would be 3.0 to 1 . A mass ratio less than 3 indicates that sulfur containing species other than water soluble sulfate are present in the waste. If the mass ratio is less than 3 , the concentration of sulfur containing species in the waste other than water soluble sulfate are calculated from the difference of these two concentrations. The calculated sulfide concentrations are compared with the threshold quantity given in SW-846 (500 mg $\mathrm{H}_{2} \mathrm{~S} / \mathrm{kg}$ of waste formed by acidification), EPA's test method for evaluating solid waste. If the sulfur concentration, after subtracting the sulfate concentration (in moles $/ \mathrm{kg}$ ), is less than $(0.0147$ moles $/ \mathrm{kg}$ of waste or $471 \mathrm{mg} / \mathrm{kg})$, the waste cannot be a sulfide-bearing waste. Sulfur and sulfate analyses from the same sample were used

(a) McNamara BK. December 2000. "Evolution of Gases from Cyanide and Sulfide Bearing Waste." Letter Report WTP-RPT-011, Battelle - Pacific Northwest Division, Richland, WA. 
for all calculations. Averages were based on the results of these calculations. "Less-than" values were not included in the calculations of the ratios or sulfide estimations.

\subsection{Cyanide}

Cyanide analyses were performed on a limited number of tank samples. Tanks B-201, B-202, T-104, and T-111 were the only tanks for which cyanide analyses were available. Process histories were analyzed to determine whether cyanide or cyanide-containing compounds may have been added to those tanks for which no analyses are available. If cyanide analyses were available, the measured cyanide concentrations were compared with the threshold values provided in EPA's SW-846 protocol (250 mg $\mathrm{HCN} / \mathrm{kg}$ of waste). If the measured concentrations were less than $241 \mathrm{mg}$ of CN/kg of waste $(241 \mu \mathrm{g} / \mathrm{g}$ of waste or ppm), the waste is not a cyanide-bearing waste.

Sodium or potassium ferrocyanide $\left[\mathrm{Na}_{4} \mathrm{Fe}(\mathrm{CN})_{6}\right.$ and $\left.\mathrm{K}_{4} \mathrm{Fe}(\mathrm{CN})_{6}\right]$ was added to some of the waste feeds along with $\mathrm{NiSO}_{4}$ and $\mathrm{NaOH}$ to precipitate sodium and cesium nickel ferrocyanides $\left[\mathrm{Na}_{2} \mathrm{NiFe}(\mathrm{CN})_{6}\right.$ and $\mathrm{Cs}_{2} \mathrm{NiFe}(\mathrm{CN})_{6}$ ], thus scavenging radiocesium from the aqueous wastes. Process histories indicate that none of these tanks accepted cyanide-containing wastes and none of the tanks were part of the cesium precipitation campaigns. None of the selected tanks were on the Ferrocyanide Watch List (Fowler 1993).

\subsection{TOC, Oxalate, and 2,4,5-Trichlorophenol}

Semivolatile organic analyses (SVOA) were performed on a few of the tank core samples. Concentrations of 2,4,5-trichlorophenol were reported as part of these analyses. If the concentration of the 2,4,5-trichlorophenol was less than the dangerous waste limit $(400 \mathrm{mg} / \mathrm{L})$, the waste was not characteristic of toxicity based on 2,4,5-trichlorophenol.

For wastes where SVOAs were not performed, TOC and oxalate analyses were used to estimate the maximum amount of 2,4,5-trichlorophenol that could potentially be available in the waste. The fraction of TOC that was present as oxalate was determined by dividing the concentration of carbon as oxalate by the TOC concentration. The fraction of TOC as oxalate was calculated for each sample that had both oxalate and TOC data. Less-than values for oxalate or TOC were not used for this estimation. This fraction was used to determine the concentration of carbon present as other organic compounds. For determining whether these wastes should carry dangerous waste designation D041 toxicity characteristics based on 2,4,5-trichlorophenol concentration, all of the organic compounds other than oxalate were considered to be 2,4,5-trichlorophenol. This is a very conservative estimate. The potential concentration of 2,4,5-trichlorophenol was then calculated according equation 4.1:

$$
\text { Concentration }=(\mathrm{TOC} \text { in } \mu \mathrm{g} / \mathrm{g}) *\left(1-\chi_{\text {oxalate }}\right) *\left(\rho_{\text {waste }}\right) *(2.74 \mathrm{~g} \mathrm{tcp} / \mathrm{g} \mathrm{C})
$$

where

$\begin{array}{ll}\text { Concentration } & =\text { the potential concentration of } 2,4,5 \text {-trichlorophenol in } \mu \mathrm{g} / \mathrm{ml} \mathrm{or} \mathrm{mg} / \mathrm{L} \\ \text { TOC } & =\text { the concentration of total organic carbon in the waste } \\ & =\text { the fraction of the total organic carbon that is present as oxalate } \\ \chi_{\text {oxalate }} & =\text { the bulk density of the waste in } \mathrm{g} / \mathrm{mL} \\ \rho_{\text {waste }} & =\text { the mass of } 2,4,5 \text {-trichlorophenol per mass of TOC. }\end{array}$




\subsection{Headspace}

Analysis of the gases present in the headspace was available on a few of the tanks of interest. Headspace samples were taken using sorbent traps for inorganic analytes and SUMMA canisters for permanent gases and total non-methane organic compounds. The canister samples were analyzed by gas chromatography, and the sorbent trap samples were determined by desorbing the analytes of interest from the trap with the appropriate aqueous solution and analyzing the solution by ion chromatography or ion selective electrode. The concentrations of these analytes were compared with their threshold limit valuetime weighed average (TLV-TWA) as reported by the American Conference of Governmental Industrial Hygienists in the 2004 Threshold Limit Values for Chemical Substances in the Work Environment (ACGIH 2004). Threshold limit values for selected analytes are provided in Table 4.3.

Table 4.3. Threshold Limit Values for Selected Headspace Gases

\begin{tabular}{||l|l||}
\hline \multicolumn{1}{|c|}{ Analyte } & \multicolumn{1}{c||}{ TLV-TWA (ppmv) } \\
\hline $\mathrm{NH}_{3}$ & 25 \\
\hline $\mathrm{NO}_{2}$ & 3 \\
\hline $\mathrm{NO}$ & 25 \\
\hline $\mathrm{CO}_{2}$ & 5000 \\
\hline $\mathrm{CO}$ & 25 \\
\hline $\mathrm{CH}_{4}$ & 1000 \\
\hline $\mathrm{H}_{2}$ & Simple asphyxiant \\
\hline $\mathrm{N}_{2} \mathrm{O}$ & 50 \\
\hline
\end{tabular}

Process wastes may be diluted prior to being retrieved from the tanks. Henry's Law states that for solutes with measurable vapor pressures, the vapor pressure of the solute in dilute solutions is proportional to the mole fraction of that solute. Based on this law used for ideal gases in dilute solutions, the concentration of gases in the headspace of the waste container will be proportional to the dilution; therefore, for process wastes that are diluted prior to retrieval from the tank, the concentration of the headspace gases can be divided by the dilution factor. If the concentrations of the headspace gases are less than the TLV-TWA for those gases, the waste does not generate toxic gases, vapors, or fumes in a large enough quantity to present a danger to human health or the environment.

\section{$4.6 \mathrm{pH}$}

Measurements of the $\mathrm{pH}$ of the tank wastes were made on most of the tanks discussed in this report. Many of these $\mathrm{pH}$ measurements were made on liquid grab samples. These $\mathrm{pH}$ measurements provide an accurate estimate of the $\mathrm{pH}$ of the waste in the tank. For some tanks, $\mathrm{pH}$ was measured on a water digest of samples that were diluted and vacuum dried similar to the proposed process for the TRUM tank wastes. This measurement followed a protocol similar protocol to that of SW-846 method 9045 in "Test Methods for Evaluating Solid Waste, Physical/Chemical Methods." If the $\mathrm{pH}$ of the tank waste samples is between 2 and 12.5 , the waste is not corrosive. 


\subsection{Summary of Characterization Data}

The existing analytical results from sampling events were reviewed and compared with the data on waste transfers in these tanks. These results are summarized for each of the three tank categories. The majority of the data were extracted from the TWINS database and characterization reports prepared by PNNL.

The analyses reported in this document were performed on wet slurries and sludges unless otherwise noted. Some of these results are reported on a dry weight basis; therefore, these results are independent of the water content of the samples. Most of the results were reported as concentration of analyte per gram of sample (wet). Once the sample is dried these concentrations will increase by the ratio of wet sample mass to dry sample mass (the reciprocal of the weight percent total solids of the sample).

Vacuum drying the retrieved tank wastes is the method proposed for removing water from the waste prior to packaging and shipping. In this process, the majority of the free water will be removed from the sample, and some volatile constituents may evaporate; but the ratios of the non-volatile constituents (e.g., sulfur and sulfate) will not change. The ratio of oxalate to TOC may actually increase if volatile organic carbon is present in the sludge, but the ratio will not decrease due to the vacuum drying process.

During the DSC analysis, water evaporates from the sample as the temperature increases; therefore, after the first endothermic transition (water loss), the results obtained from the DSC provide the energetics of the dried sample. Corrosivity of dried samples is obtained by adding water to the sample and measuring the $\mathrm{pH}$ of the resulting supernatant liquor; therefore, the $\mathrm{pH}$ of the wet sludge provides the data required to determine the corrosivity of the dried solids.

\subsection{Series Tanks (B and T Tank Farms)}

Thermal analysis was performed in duplicate on direct subsamples from segments and core composites of all of the 200 series tanks in the B and $\mathrm{T}$ farms and on some liquid grab samples from the tanks. TGA and either DSC or differential thermal analysis (DTA), which provide similar data, were performed on each sample. A single endothermic transition was observed in many of the samples, but two were observed in some of them. In one sample that was dried (segment 3 of core 27 from Tank B-201), a third endothermic transition was observed. The first endotherm was observed in all the samples except the dried sample and occurred between ambient temperature and $150^{\circ} \mathrm{C}$. This endothermic transition coincides with mass loss observed in the TGA and indicates the evaporation of free water from the sample. The enthalpy of this endothermic transition was dependent on the water content of the sample. The second endothermic transition was observed between $200^{\circ}$ and $330^{\circ} \mathrm{C}$. This endotherm is also associated with weight loss on the TGA; therefore, it is probably due to loss of more tightly bound water such as waters of hydration. The third endothermic transition was much smaller and was observed at higher temperatures. A small weight loss $(\sim 2 \mathrm{wt} \%)$ is associated with this transition. Because this same weight loss was observed in many of the other samples, this endotherm may be present in other samples but not readily observed because the enthalpy of this endotherm is so much smaller than the water loss endotherms in wet samples. These transitions are probably due to the loss of waters of hydration, phase transitions, or decomposition of salts and hydroxides to oxides. 
No significant exothermic behavior was observed in the 200 series tanks in T farm or in Tanks B-201 and B-204. The maximum enthalpy observed for these samples was $16.7 \mathrm{~J} / \mathrm{g}$ of waste on a dry weight basis in an aliquot from segment 9 of core 190 (Tank T-203). An exotherm was observed in duplicate aliquots of several segments from Tank B-202 (segments 2, 4, 5, and 8 of core 24 and segments 1, 2, 3, 6, 7 , and 8 of core 25) and in two of 48 samples from B-203. All of the exothermic transitions were broader peaks with smaller amplitudes than the endothermic transitions. The exothermic transitions from Tank B-202 and the solid samples from B-203 began near $250^{\circ} \mathrm{C}$ and ended near $450^{\circ} \mathrm{C}$ with enthalpies between -30 and $-172.7 \mathrm{~J} / \mathrm{g}$ of waste. A liquid grab sample analyzed by DSC also appeared to exhibit significant exothermic behavior $(\Delta \mathrm{H}=-176 \mathrm{~J} / \mathrm{g})$. The duplicate and triplicate samples did not exhibit the same behavior. The duplicate sample indicated an endotherm at this temperature range; the triplicate sample indicated a slight exotherm between $430^{\circ}$ and $500^{\circ} \mathrm{C}$, but the enthalpy was only $-33.7 \mathrm{~J} / \mathrm{g}$.

Sulfur and/or sulfate analyses were performed on segments from the core samples divided into the lower and upper half, core composites, and/or drainable liquids from the core samples. Analyses were performed on some samples from all of the B- and T-200 series tanks. The type and number of samples analyzed for sulfur and sulfate from each tanks are reported in Table 5.1. Many of the results from these samples were below the quantification limits, and only less-than values were reported. Tanks for which only less-than values were reported are noted in the table.

Table 5.1. Sulfur and Sulfate Analyses for the B- and T-200 Series Tanks

\begin{tabular}{|c|c|c|c|c|c|c||}
\hline \multirow{3}{*}{ Tank } & \multicolumn{7}{|c||}{ Number of Samples } \\
\cline { 2 - 7 } & \multicolumn{7}{|c|}{ Sulfur Analysis } & \multicolumn{3}{c||}{ Sulfate Analysis } \\
\cline { 2 - 7 } & Segment & Composite & Liquid & Segment & Composite & Liquid \\
\hline B-201 & None & None & None & None & 4 & None \\
\hline B-202 & None & 6 & None & None & 6 & None \\
\hline B-203 & 41 & None & 3 & 41 & None & 3 \\
\hline B-204 & 49 & None & 3 & 49 & None & 3 \\
\hline T-201 & $6^{(\text {a) }}$ & None & 5 & 6 & None & $5^{(\text {a) }}$ \\
\hline T-202 & 6 & None & None & 6 & None & None \\
\hline T-203 & 20 & None & 1 & 20 & None & 1 \\
\hline T-204 & None & $1^{\text {(a) }}$ & None & None & $1^{(\text {a) }}$ & None \\
\hline (a) All results were reported as less than values. \\
\hline
\end{tabular}

The majority of the results indicate that the sulfur in these wastes exists primarily as sulfate. Only seven samples had $\mathrm{SO}_{4}{ }^{2}$-to-S ratios less than 2.8, and many of these had ratios greater than 2.4. These ratios indicate that the sulfur is present predominantly in the sulfate form.

Cyanide analyses were performed on core composites and drainable liquids from Tanks B-201 and B-202 and on a single segment from Tank B-203. The results of these analyses are reported in Table 5.2. Cyanide analyses were not performed on Tank B-204 or any of the T-200 series tanks. These analyses were done in duplicate by three different methods. Water digests of the samples from Tanks B-201 and B-202 were analyzed by ion chromatography and spectrophotometry at $580 \mathrm{~nm}$, respectively. The solids from the single segment from Tank B-203 (core 122, lower half of segment 10) were analyzed by a method that incorporates cyanide complexes. The majority of the results were below the quantification 
Table 5.2. Cyanide Analyses for the B- and T-200 Series Tanks

\begin{tabular}{|c|c|c|c||}
\hline \hline Tank & Core & Sample & Concentration $(\boldsymbol{\mu g} / \mathbf{g})$ \\
\hline & 26 & Composite 1 & 5 \\
\cline { 2 - 4 } & & Composite 2 & 3.95 \\
\cline { 2 - 4 } & 27 & Composite 1 & $<3$ \\
\cline { 2 - 4 } B-202 & & Composite 2 & $<2$ \\
\cline { 2 - 4 } & 4 & Composite & $<0.5$ \\
\cline { 2 - 5 } & 5 & Composite & $<2.5$ \\
\cline { 2 - 4 } & 10 & Composite & $<2.44$ \\
\cline { 2 - 4 } & 11 & Composite & $<0.5$ \\
\hline & & Composite & $<8$ \\
\hline & 16 & Drainable liquid & $<0.5 \mu \mathrm{g} / \mathrm{ml}$ \\
\hline B-203 & 122 & Segment 10 & $<5.91$ \\
\hline \hline
\end{tabular}

limit, and less-than values were reported. The less-than values ranged from 0.5 to $8 \mu \mathrm{g} / \mathrm{g}$, with most less than $2.5 \mu \mathrm{g} / \mathrm{g}$. Only two results were reported as actual values. Both of these results were from Tank B-201, core 26. These results (4 and $5 \mu \mathrm{g} / \mathrm{g}$ ) were within the range of the less-than values reported and well below the $241 \mu \mathrm{g} / \mathrm{g}$ required for a waste to be considered a cyanide-bearing waste. None of the B- or T-200 series tanks were on the Ferrocyanide Watch List (Fowler 1993), and cyanide-containing wastes and/or process streams were not introduced into these tanks.

Semi-volatile organic analysis (SVOA) was performed on samples from Tanks B-201 and B-202. The concentrations of 2,4,5-trichlorophenol in these samples were less than 240 and $150 \mu \mathrm{g} / \mathrm{g}$, respectively. No other SVOA results were reported on the B- and T-200 series tanks. Both TOC and/or oxalate analyses were performed on the other tanks. The range of concentrations obtained for these analyses are reported in Table 5.3. No TOC analyses were performed on samples from Tanks B-204 or

Table 5.3. TOC and Oxalate Results for the B- and T-200 Series Tanks

\begin{tabular}{|c|l|c|c|c|c||}
\hline \multirow{2}{*}{ Tank } & \multirow{2}{*}{ Sample Type } & \multicolumn{2}{|c|}{ TOC $(\boldsymbol{\mu g} / \mathbf{g})$} & \multicolumn{2}{c||}{ Oxalate $(\boldsymbol{\mu g} / \mathbf{g})$} \\
\cline { 3 - 6 } & & $\begin{array}{c}\text { Persulfate } \\
\text { Oxidation }\end{array}$ & $\begin{array}{c}\text { Furnace } \\
\text { Oxidation }\end{array}$ & As Oxalate & As Carbon \\
\hline B-201 & Core Composite & $575-4,500$ & - & - & - \\
\hline B-202 & Core Composite & - & $2,020-3,770$ & - & - \\
\hline B-203 & Segment & 72 & - & $811-16,600$ & $157-3200$ \\
\hline B-203 & Drainable Liquid & $96 \mu \mathrm{g} / \mathrm{mL}$ & - & $486 \mu \mathrm{g} / \mathrm{mL}$ & $94 \mu \mathrm{g} / \mathrm{mL}$ \\
\hline B-204 & Segment & - & - & $450-2,400$ & $87-463$ \\
\hline B-204 & Drainable Liquid & - & - & 753 & 145 \\
\hline T-201 & Composite \& Segments & $133-304$ & - & $682-1,140$ & $132-220$ \\
\hline T-201 & Drainable Liquid & - & - & $<223$ & $<43$ \\
\hline T-202 & Composite \& Segment & 347 & - & $372-1,510$ & $72-291$ \\
\hline T-203 & Composite \& Segment & 421 & - & $283-1,590$ & $55-307$ \\
\hline T-203 & Drainable Liquid & - & - & $<223$ & $<43$ \\
\hline T-204 & Composite & 312 & - & 1,330 & 257 \\
\hline
\end{tabular}


on the drainable liquid composites from Tanks T-201 and T-203. Only results below the quantification limit were obtained for oxalate in the drainable liquids from Tanks T-201 and T-203, and no oxalate analyses were performed on Tanks B-201 and B-202. The ranges reported in Table 5.3 include results above the quantification limit unless only less-than values were reported.

The fraction of the TOC that was present as oxalate could not be determined for the solids from the B-200 series tanks because the quantifiable oxalate and TOC values were not obtained on the same samples. In the T-200 series tanks and the drainable liquid from Tank B-203, the majority of the TOC appears to be present as oxalate. For the samples that had both TOC and oxalate values, the fraction of TOC that was present as oxalate was approximately $75 \%$.

Mercury concentrations in the composites of cores 26 and 27 from Tank B-201 and 4, 5, 10, and 11 from Tank B-202 were measured by cold vapor atomic absorption (CVAA). Leachable mercury from TCLP solutions that were digested in acid from core 27 composites was also measured by CVAA. Leachable mercury from TCLP and acid digestion from core 5 and 10 composites were measured by atomic absorption (AA) and acid digestion of core 4, 5, and 10 composites. The direct samples are a better indicator of mercury concentration, but TCLP samples provide data on leachable mercury. Mercury results are reported in Table 5.4. All TCLP samples were below $0.077 \mu \mathrm{g} / \mathrm{mL}$. The direct samples and acid digestions of the core composites ranged from $<0.123$ to $1.1 \mu \mathrm{g} / \mathrm{g}$. Mercury concentrations were significantly higher in B-201 than B-202. No mercury data are available on the other tanks.

Table 5.4. Mercury Analyses for the B- and T-200 Series Tanks

\begin{tabular}{|c|c|c|c|}
\hline \multicolumn{4}{|c|}{ Cold Vapor Atomic Absorption } \\
\hline Tank & Core & Sample & Concentration $(\mu \mathrm{g} / \mathrm{g})$ \\
\hline \multirow{6}{*}{ B-201 } & \multirow{2}{*}{26} & Composite 1 & 1 \\
\hline & & Composite 2 & 0.75 \\
\hline & \multirow{4}{*}{27} & Composite 1 & 0.54 \\
\hline & & Composite 2 & 0.11 \\
\hline & & TCLP Composite 1 & $0.025 \mu \mathrm{g} / \mathrm{mL}$ \\
\hline & & TCLP Composite 2 & $0.003 \mu \mathrm{g} / \mathrm{mL}$ \\
\hline \multirow{6}{*}{ B-202 } & 4 & Composite & 0.27 \\
\hline & \multirow{2}{*}{5} & Composite & 0.33 \\
\hline & & Composite & 0.74 \\
\hline & \multirow{2}{*}{10} & Composite & $<0.12$ \\
\hline & & Composite & 0.26 \\
\hline & 11 & Composite & 0.26 \\
\hline \multicolumn{4}{|c|}{ Atomic Absorption } \\
\hline \multirow{6}{*}{ B-202 } & 4 & Composite & $<0.49$ \\
\hline & \multirow{3}{*}{5} & Composite & $<0.49$ \\
\hline & & TCLP Composite & 0.077 \\
\hline & & TCLP Composite & 0.056 \\
\hline & \multirow{2}{*}{10} & Composite & $<0.49$ \\
\hline & & TCLP Composite & $<0.05$ \\
\hline
\end{tabular}


The $\mathrm{pH}$ of the waste was measured on core or tank composites from Tanks B-201, B-202, B-203, T-203, and T-204. The $\mathrm{pH}$ of water leaches (ratio of 100:1 water to sample) was also measured on B-201. The results of these $\mathrm{pH}$ measurements are provided in Table 5.5. The $\mathrm{pH}$ of the supernatant liquor from multiple dilutions of a Tanks B-203, T-203, and T-204 composite were also measured and did not vary over the range of dilutions (as-received waste to a 4:1 water-to-waste dilution). The average $\mathrm{pH}$ value for each tank composite measured in this supernatant liquor is also reported in Table 5.5 (Tingey et al. 2003). The $\mathrm{pH}$ of these samples did not exceed the 12.5 limit for corrosive wastes.

Gas analysis was performed on vapor taken from headspace of Tanks B-202, B-204, T-201, T-202, $\mathrm{T}-203$, and T-204. The highest measured concentration of each of the gases in any of the B- or T-200 series tanks is reported in Table 5.6. These gases represent less than $2 \%$ of the lower flammability limit (LFL). None exceeded the TLV-TWA.

Table 5.5. $\mathrm{pH}$ of the B- and T-200 Series Tanks

\begin{tabular}{|c|c|c|c||}
\hline \multirow{2}{*}{ Tank } & \multicolumn{3}{|c|}{ pH } \\
\cline { 2 - 4 } & Composite & Water Leach & Dilutions \\
\hline B-201 & 12.3 & $8.5 \pm 0.05$ & -- \\
\hline B-202 & $12.3 \pm 0.15$ & -- & -- \\
\hline B-203 & 10.5 & -- & $11.4 \pm 0.10$ \\
\hline T-203 & 10.9 & -- & $11.0 \pm 0.06$ \\
\hline T-204 & 9.84 & -- & $11.0 \pm 0.05$ \\
\hline
\end{tabular}

Table 5.6. Headspace Analysis for the B- and T-200 Series Tanks

\begin{tabular}{||l|l||}
\hline \multicolumn{1}{|c|}{ Analyte } & $\begin{array}{c}\text { Vapor Concentration } \\
\text { (ppmv) }\end{array}$ \\
\hline $\mathrm{NH}_{3}$ & 8 \\
\hline $\mathrm{NO}_{2}$ & $<0.16$ \\
\hline $\mathrm{NO}$ & $<0.16$ \\
\hline $\mathrm{H}_{2} \mathrm{O}$ & $14 \mathrm{mg} / \mathrm{L}$ \\
\hline $\mathrm{CO}_{2}$ & 696 \\
\hline $\mathrm{CO}$ & $<3$ \\
\hline $\mathrm{CH}_{4}$ & $<4$ \\
\hline $\mathrm{H}_{2}$ & $<17$ \\
\hline $\mathrm{N}_{2} 0$ & $<17$ \\
\hline Total non-methane organic compounds & $0.86 \mathrm{mg} / \mathrm{m}^{3}$ \\
\hline
\end{tabular}

Because exothermic behavior was observed only at temperatures exceeding $250^{\circ} \mathrm{C}$, and all of the exothermic transitions were broader peaks and smaller amplitudes than the endothermic transitions, the waste can be considered to be thermally stable. These results also indicate that the waste will not form potentially explosive mixtures with water, will not detonate or undergo an explosive reaction if heated, and will not detonate or decompose explosively at standard temperature and pressure. These results, along with the low concentrations of flammable gases present in the headspace $(<2 \%$ of the LFL), 
indicate that this waste does have ignitable characteristics. The waste is not cyanide- or sulfide-bearing and does not contain 2,4,5-trichlorophenol at concentrations exceeding the dangerous waste limits. None of the toxic gases observed in the headspace are above the TLV-TWA; therefore, toxic gases, vapors, or fumes should not be generated at concentrations hazardous to human health.

\subsection{T-100 Series Tanks (241-T-110 and 241-T-111)}

Thermal analysis was performed in duplicate on samples from both the upper and lower halves of all segments from cores 180 and 181 of Tank T-110. Thermal analysis was also performed on samples from all segments of cores 31 and 33 of Tank T-111. The DSC analysis from segment 2 of core 33 was repeated on dried samples multiple times. Analysis was also repeated on dried samples from segment 1 of core 33. Both TGA and DSC were performed on each sample.

A single endothermic transition was observed in many of the T-110 samples, but two were observed in some of them. The first endotherm was observed in all of the samples and occurred between ambient temperature and $150^{\circ} \mathrm{C}$. This endothermic transition coincides with mass loss observed in the TGA and is indicative of the evaporation of the free water from the sample. The enthalpy of this endothermic transition was dependent upon the water content of the sample. The second endothermic transition was observed between $240^{\circ}$ and $340^{\circ} \mathrm{C}$ with an onset temperature of approximately $300^{\circ} \mathrm{C}$. No apparent mass loss was observed in the TGA over this temperature range; therefore, this second endotherm is probably due to a phase transition or the decomposition of hydroxides to oxides. An exotherm was observed in the sample from the upper half of segment 5 of core 181. The enthalpy of this exotherm was $12.6 \mathrm{~J} / \mathrm{g}$ over a temperature range from $450^{\circ}$ to $500^{\circ} \mathrm{C}$. This exotherm was not observed in the duplicate sample.

A single endothermic transition followed by a significant but broad exothermic reaction was observed on segments 1, 2, and 3 of core 31 and segments 1 and 2 of core 33 from Tank T-111. The lower segments (segment 4 of core 31 and segments 3 and 4 of core 33) exhibited minimal or no exothermic behavior. The initial endotherm was similar to the first one observed in Tank T-110 and indicates evaporation of free water. The exotherm does not coincide with a mass loss and appears to represent the oxidation of the organic carbon in the waste. The enthalpy of this exothermic reaction on wet samples was significantly smaller than the water endotherm and ranged from 250 to $650 \mathrm{~J} / \mathrm{g}$. Segment 2 of core 33 had the largest enthalpy. The water loss endotherm generally exceeded $1000 \mathrm{~J} / \mathrm{g}$. The temperature range of the exotherm was consistent for all of the samples and ranged from $200^{\circ}$ to $400^{\circ} \mathrm{C}$.

Similar results were observed for the dried samples from segment 2 of core 33 except the water loss endotherm was much smaller because most of the water was removed before the analyses. On a few samples, all of the water was removed prior to the measurements, and this water loss endotherm did not exist. On these samples the onset temperature of the exotherm was $199^{\circ} \mathrm{C}$ with an enthalpy of approximately $900 \mathrm{~J} / \mathrm{g}$.

Neither sulfur nor sulfate analyses were performed on core samples from Tank T-110 but were obtained on a grab sample. Both sulfate and sulfur data are available on the core composites from Tank T-111 (cores 31 and 33) as are sulfur analysis data on segment 9 of core 31 . Results from these analyses as well as the ratio of sulfate to sulfur are reported in Table 5.7. Based on these analyses, the majority of the sulfur is present as sulfate. 
Table 5.7. Sulfur and Sulfate Concentrations in Tanks T-110 and T-111

\begin{tabular}{||c|c|c|c|c||}
\hline Tank & Sample & Sulfur $(\boldsymbol{\mu g} / \mathbf{g})$ & Sulfate $(\boldsymbol{\mu g} / \mathbf{g})$ & Sulfate/Sulfur Ratio \\
\hline T-110 & Grab Sample 10T-96-1 & 1590 & 4360 & 2.7 \\
\hline \multirow{4}{*}{ T-111 } & Core 31 Composite 1 & 1230 & 3690 & 3.0 \\
\cline { 2 - 5 } & Core 31 Composite 2 & 1270 & 3740 & 2.9 \\
\cline { 2 - 5 } & Core 31 Segment 9 & 1480 & 5120 & 3.5 \\
\cline { 2 - 5 } & Core 33 Composite 1 & 1140 & 3290 & 2.9 \\
\cline { 2 - 5 } & Core 33 Composite 2 & 1220 & 3470 & 2.8 \\
\hline
\end{tabular}

Cyanide analyses were performed on composites from cores 31 and 33 of Tank T-111 and on water digests of segments 1 and 2 from core 33. The cyanide analyses were performed by two methods on the water digest from segment 2. Cyanide analyses were not performed on Tank T-110 samples. The majority of analyses were done by spectrophotometry at $580 \mathrm{~nm}$, but one of the water digests on segment 2 was analyzed using a method incorporating cyanide complexes. The majority of the results (Table 5.8) are below the detection limit and were reported as less-than values. These less-than values ranged from 0.049 to $5 \mu \mathrm{g} / \mathrm{g}$. Only three results were reported as actual values. Two of these results from the core 33 composites were within the range of the less-than values $(3.72$ and $2.47 \mu \mathrm{g} / \mathrm{g})$; the third was obtained from segment 1 and was much higher than any of the other results $(57.6 \mu \mathrm{g} / \mathrm{g})$ but still well below the $241 \mu \mathrm{g} / \mathrm{g}$ required for a waste to be considered cyanide bearing. Neither of these tanks is on the Ferrocyanide Watch List (Fowler 1993), and cyanide-containing wastes, and/or process streams were not introduced into these tanks.

Table 5.8. Cyanide Analyses of Tank T-111 Samples

\begin{tabular}{||c|c|c||}
\hline Core & Sample & Concentration $(\boldsymbol{\mu g} \mathbf{g} \mathbf{g})$ \\
\hline \multirow{3}{*}{31} & Composite 1 & $<4.3$ \\
\cline { 2 - 3 } & Composite 2 & $<3.5$ \\
\hline \multirow{4}{*}{33} & Composite 1 & $<4.9$ \\
\cline { 2 - 3 } & Composite 2 & $<4.7$ \\
\cline { 2 - 3 } & Segment 1 & 3.72 \\
\cline { 2 - 3 } & Segment 2 & 2.47 \\
\cline { 2 - 3 } & Segment 1 Water Digest & 57.6 \\
\cline { 2 - 3 } & Segment 1 Water Digest & $<2.7$ \\
\cline { 2 - 3 } & Segment 2 Water Digest & $<0.05$ \\
\hline
\end{tabular}

SVOA was performed on composite samples from cores 31 and 33 of Tank T-111. The concentrations of 2,4,5-trichlorophenol in these samples were below the detection limit, and less-than values ranged from 65 to $120 \mu \mathrm{g} / \mathrm{g}$. No SVOA data were available for Tank T-110. These values are well below the dangerous waste limit of $400 \mu \mathrm{g} / \mathrm{g}$.

No oxalate data were obtained on Tank T-111, and a less-than value for oxalate $(<556 \mu \mathrm{g} / \mathrm{mL})$ and a single value for TOC from one grab sample (10T-96-1) were the only data available on Tank T-110. The TOC for Tank T-110 was reported to be $45 \mu \mathrm{g} / \mathrm{mL}$. Both the 222-S Laboratory and PNNL performed 
TOC analyses on samples from cores 31 and 33 from Tank T-111. Furnace oxidation of water digest samples was performed at the 222-S Laboratory. Both hot persulfate and furnace oxidation methods were performed at PNNL on dried samples from segment 2 of core 33. ${ }^{\text {(a) }}$ The furnace oxidation method on dried samples appeared to provide the most accurate values that were consistent with the exothermic behavior described earlier. The TOC results on the water leach on cores 31 and 33 were 3740 and $2500 \mu \mathrm{g} / \mathrm{g}$, respectively. TOC results of the hot persulfate oxidation of the segment 2 sample were consistent with these results $(3460 \mu \mathrm{g} / \mathrm{g})$. TOC of the grab sample was much lower $(420 \mu \mathrm{g} / \mathrm{g})$. The TOC of the wet sludge ( $18 \%$ solids) measured by furnace oxidation at PNNL was $0.89 \%$. The dried sludge results were approximately four times lower by hot persulfate than by furnace oxidation, which is consistent with the wet sludge results $(4.09 \%$ TOC, which, when corrected for water content, is equivalent to $0.74 \%$ for the wet sludge). The TOC is expected to be higher in segment 2 than in the core composites based on the exothermic behavior of segment 2 compared with the lower segments from the core. The exothermic behavior of the top three segments was much higher than that observed in the lower three segments.

Mercury concentrations in the composites of cores 31 and 33 from Tank T-111 were measured directly by CVAA and on acid digestions of the TCLP leach samples by AA. The direct samples give a better indication of the mercury concentrations in the sample, but the TCLP samples provide data on the leachable mercury in the waste. All of the TCLP samples were below the detection limit of approximately $0.045 \mu \mathrm{g} / \mathrm{mL}$. The direct samples ranged from 1.08 to $1.59 \mu \mathrm{g} / \mathrm{g}$. No mercury data are available on Tank T-110.

The $\mathrm{pH}$ of the waste was measured on water digests of the core 31 and 33 composites from Tank $\mathrm{T}-111$ and on grab samples from both $\mathrm{T}-110$ and $\mathrm{T}-111$. The measured $\mathrm{pH}$ values were consistent for both composites from T-111. The measured $\mathrm{pH}$ was $9.98 \pm 0.17$. The $\mathrm{pH}$ of the grab sample taken in 1994 (11.7) was significantly higher than the water digest of the core composites, but both were well below the 12.5 limit for corrosive wastes. The $\mathrm{pH}$ measured on the grab samples from Tank $\mathrm{T}-110$ (samples 10T-96-1, 10T-96-2, and 10T-96-3) were significantly lower than the $\mathrm{pH}$ of Tank T-111 but consistent with one another. The measured $\mathrm{pH}$ for $\mathrm{T}-110$ was $8.42 \pm 0.03$. The $\mathrm{pH}$ of the supernatant liquor from multiple dilutions of a Tank T-110 composite was found to be consistent with the grab sample results and did not vary over the range of dilutions (as-received waste to a 4:1 water-to-waste dilution). The $\mathrm{pH}$ values measured in these supernatant liquors was $8.28 \pm 0.02$ (Tingey et al. 2003). Gas analysis was performed on vapor taken from headspace of both T-110 and T-111 (Huckaby and Bratzel 1995). The results of these analyses are summarized in Table 5.9. The gases represent less than $0.2 \%$ of the LFL.

(a) Baldwin DL. January 14, 1994. "Final T-111 (Core 33, Segment 2) Dry/As-Received TOC Results from Two Methods," Revision 2. Letter to RM Bean. 
Table 5.9. Headspace Analysis for Tanks $\mathrm{T}-110$ and $\mathrm{T}-111$

\begin{tabular}{|l|c|c||}
\hline \multirow{2}{*}{\multicolumn{1}{|c|}{ Analyte }} & \multicolumn{2}{c|}{ Vapor Concentration (ppmv) } \\
\cline { 2 - 3 } & T-110 & T-111 \\
\hline $\mathrm{NH}_{3}$ & 108 & 226 \\
\hline $\mathrm{NO}_{2}$ & $<0.05$ & $<0.09$ \\
\hline $\mathrm{NO}$ & $<0.06$ & $<0.06$ \\
\hline $\mathrm{H}_{2} \mathrm{O}$ & $16.9 \pm 0.2 \mathrm{mg} / \mathrm{L}$ & $11.8 \mathrm{mg} / \mathrm{L}$ \\
\hline $\mathrm{CO}_{2}$ & $358 \pm 3$ & 69 \\
\hline $\mathrm{CO}$ & $<25$ & $<12$ \\
\hline $\mathrm{CH}_{4}$ & $<25$ & -- \\
\hline $\mathrm{H}_{2}$ & $<25$ & $<94$ \\
\hline $\mathrm{N}_{2} \mathrm{O}$ & $<25$ & $<12.6$ \\
\hline Total non-methane organic compounds & $1.12 \pm 0.27 \mathrm{mg} / \mathrm{m}^{3}$ & -- \\
\hline
\end{tabular}

The retrieval process planned for Tanks T-110 and T-111 will likely result in dilution of the waste. Based on Henry's Law for dilute solutions, concentrations of an ideal gas will be diluted proportional to the dilution of the solute; therefore, an estimate of the concentration of these headspace gases above the process waste retrieved from the tank should include this dilution factor. A dilution factor of 4.3 would be required to dilute the $\mathrm{NH}_{3}$ concentration in the vapor below the TLV-TWA of 25 ppmv in Tank T-110, and a dilution factor of about 9 in Tank T-111 would be required to achieve the same effect. All of the other gases are below the TLV-TWA.

Because no exothermic behavior was observed at normal temperatures and pressures and the quantity of flammable gases present in the headspace is less than $0.2 \%$ of the LFL, this waste is not ignitable. The energetics of the system also indicates that the waste is thermally stable below $200^{\circ} \mathrm{C}$, does not form potentially explosive mixtures with water, and does not detonate or decompose explosively at standard temperature and pressure. The waste is not a cyanide- or sulfide-bearing waste and does not contain 2,4,5-trichlorophenol at concentrations exceeding the dangerous waste limits. The only toxic gas observed in the headspace above the TLV-TWA is $\mathrm{NH}_{3}$. The process wastes retrieved from the tank will require a dilution factor of at least 4.3 for Tank T-110 and 9 for Tank T-111 (or other mitigation methods) to ensure that toxic gases, vapors, or fumes will not be generated at concentrations that are hazardous to human health.

The energetics of Tank T-110 waste is significantly different than T-111 waste, and T-110 waste is thermally stable over the entire temperature range of the DSC measurements (ambient to $500^{\circ} \mathrm{C}$ ). Oxidation of organic compounds in T-111 waste results in a significant release of energy at temperatures above $200^{\circ} \mathrm{C}$ when the waste is dried. Under current tank conditions (significant moisture associated with the sludge), the endothermic transition due to the evaporation of water is much larger than the exothermic reaction. The exothermic behavior of Tank T-111 wastes is not observed at temperatures below $200^{\circ} \mathrm{C}$, does not form potentially explosive mixtures with water, and does not detonate or decompose explosively at standard temperature and pressure. 


\subsection{T-100 Series Tank 1C (241-T-104)}

Thermal analysis was performed in duplicate on samples of both segments and composites from cores 45 and 46. Both TGA and DSC were performed on each sample. A single endothermic transition was observed for all samples; this endothermic transition coincides with mass loss observed in the TGA and is indicative of the evaporation of free water from the sample. The enthalpy of this endothermic transition was dependent upon the water content of the sample, and the temperature range of the transition was ambient to $150^{\circ} \mathrm{C}$. No exothermic behavior was observed in any of these samples. Detailed results, including the plots of the DSC and TGA analyses, can be found in WHC (1993).

Sulfur analyses were performed on acid digests of the core composite samples from cores 45 and 46 and on water digests of these same samples. Both sulfur and sulfate analyses were performed on the drainable liquid composite from core 46. The sulfate/sulfur ratio was calculated to determine whether sulfur was present in a form other than sulfate. The ratios indicated the sulfur was present predominantly in the sulfate form. These results are reported in Table 5.10.

Cyanide analyses were performed in duplicate on core composites from cores 45 and 46 and on a drainable liquid composite from core 46. The majority of the results were below the detection limit, and a less-than value of $2 \mu \mathrm{g} / \mathrm{g}$ was reported for all core composite samples (Table 5.11). The cyanide concentration in the drainable liquid sample was $0.7 \mu \mathrm{g} / \mathrm{mL}$. These results are well below the $241 \mu \mathrm{g} / \mathrm{g}$ required for a waste to be considered cyanide bearing. Tank T-104 is not included on the Ferrocyanide Watch List (Fowler 1993) and does not contain cyanide wastes or process stream waste.

Table 5.10. Sulfur and Sulfate Concentrations in Tank T-104

\begin{tabular}{|l|c|c|c|}
\hline \multicolumn{1}{|c|}{ Sample } & Sulfur $(\boldsymbol{\mu g} / \mathbf{g})$ & Sulfate $(\boldsymbol{\mu g} / \mathbf{g})$ & Sulfate/Sulfur Ratio \\
\hline Core 45 Composite 1 & 1250 & 3880 & 3.1 \\
\hline Core 45 Composite 2 & 1350 & 3920 & 2.9 \\
\hline Core 46 Composite 1 & 1270 & 3920 & 3.1 \\
\hline Core 46 Composite 2 & 1250 & 3870 & 3.1 \\
\hline Core 46 Drainable Liquid & 1700 & 4260 & 2.5 \\
\hline
\end{tabular}

Table 5.11. Cyanide Analyses of Tank T-104 Samples

\begin{tabular}{|c|l|c||}
\hline \hline Core & \multicolumn{1}{|c|}{ Sample } & Concentration $(\boldsymbol{\mu g} / \mathbf{g})$ \\
\hline \multirow{2}{*}{45} & Composite 1 & $<2.0$ \\
\cline { 2 - 3 } & Composite 2 & $<2.0$ \\
\hline \multirow{3}{*}{46} & Composite 1 & $<2.0$ \\
\cline { 2 - 3 } & Composite 2 & $<2.0$ \\
\cline { 2 - 3 } & Drainable Liquids & $0.70 \mu \mathrm{g} / \mathrm{mL}$ \\
\hline
\end{tabular}

SVOA was performed on composite samples from cores 45 and 46 . The concentration of 2,4,5trichlorophenol in the samples was less than $53 \mu \mathrm{g} / \mathrm{g}$. TOC was analyzed by furnace oxidation on water digests of the core 45 and 46 composites. These analyses were performed on water digestion, so only the water-soluble fraction of the organic carbon would be present, but the solubility of 2,4,5-trichlorophenol 
in water was $1,000 \mu \mathrm{g} / \mathrm{g}$ at $25^{\circ} \mathrm{C}$. The majority of the results were below the detection limit, $550 \mu \mathrm{g} / \mathrm{g}$. The duplicate run of the core 45 composite did give a quantifiable result of $706 \mu \mathrm{g} / \mathrm{g}$. A TOC concentration of $451 \mu \mathrm{g} / \mathrm{mL}$ was measured on an undigested sample of the drainable liquid composite from core 46. No oxalate analyses were performed. The 2,4,5-trichlorophenol concentrations measured are well below the dangerous waste limit $(400 \mu \mathrm{g} / \mathrm{g})$. The results indicate that the water-soluble TOC concentration in this tank is just slightly higher than the limit for 2,4,5-trichlorophenol; therefore, over $55 \%$ of the water soluble organic carbon would need to be 2,4,5-trichlorphenol to exceed this limit.

Mercury concentrations in the composites of core 45 and 46 were measured by CVAA. The majority of the analyses were below the detection limit of $0.125 \mu \mathrm{g} / \mathrm{g}$. The duplicate analysis from the core 45 composite 1 was slightly above the detection limit, with a reported value of $0.127 \mu \mathrm{g} / \mathrm{g}$.

The pH of Tank T-104 was measured directly on undigested composites from cores 45 and 46 and on the composite of drainable liquids from core 46 . The measured $\mathrm{pH}$ value was $9.99 \pm 0.03$. The $\mathrm{pH}$ of the drainable liquids (9.95) appeared to be slightly lower than the core composites $(10.00 \pm 0.01)$ but well within normal measurement error. Table 5.12 lists results. Gas analysis was performed on vapor from the headspace of the tank (Pool et al. 1996). The results are summarized in Table 5.13. These gases represent less than $0.2 \%$ of the LFL.

Table 5.12. $\mathrm{pH}$ of Tank T-104 Samples

\begin{tabular}{|c|c|c|}
\hline Core & Sample & pH \\
\hline \multirow{2}{*}{45} & Composite 1 & 10.00 \\
\cline { 2 - 3 } & Composite 2 & 10.00 \\
\hline \multirow{3}{*}{46} & Composite 1 & 10.02 \\
\cline { 2 - 3 } & Composite 2 & 9.99 \\
\cline { 2 - 3 } & Drainable Liquids & 9.95 \\
\hline
\end{tabular}

Table 5.13. Headspace Analysis for Tank T-104

\begin{tabular}{|l|l|}
\hline \multicolumn{1}{|c|}{ Analyte } & Vapor Concentration (ppmv) \\
\hline $\mathrm{NH}_{3}$ & $105 \pm 3$ \\
\hline $\mathrm{NO}_{2}$ & $0.3 \pm 0.1$ \\
\hline $\mathrm{NO}$ & $0.3 \pm 0.2$ \\
\hline $\mathrm{H}_{2} \mathrm{O}$ & $12.0 \pm 0.5 \mathrm{mg} / \mathrm{L}$ \\
\hline $\mathrm{CO}_{2}$ & 241 \\
\hline $\mathrm{CO}$ & $<3$ \\
\hline $\mathrm{CH}_{4}$ & $<4$ \\
\hline $\mathrm{H}_{2}$ & $12^{*}$ \\
\hline $\mathrm{N}_{2} \mathrm{O}$ & $8^{*}$ \\
\hline Total non-methane organic compounds & $1.93 \mathrm{mg} / \mathrm{m}^{3}$ \\
\hline $\begin{array}{l}\text { (a) Target compound detected above the instrument detection limit (IDL) but } \\
\text { below the estimated quantitation limit (EQL). }\end{array}$ \\
\hline
\end{tabular}


The retrieval process planned for Tank T-104 will likely result in dilution of the waste. Based on Henry's Law for dilute solutions, concentrations of an ideal gas will be diluted proportional to the dilution of the solute; therefore, an estimate of the concentration of these headspace gases above the process waste retrieved from the tank should include this dilution factor. A dilution factor of 4.2 would be required to dilute the $\mathrm{NH}_{3}$ concentration in the vapor below the TLV-TWA of 25 ppmv.

Because no exothermic behavior was observed and the quantity of flammable gases present in the headspace is less than $0.2 \%$ of the LFL, this waste is not ignitable. The energetics of the system also indicates that the waste is thermally stable, does not form potentially explosive mixtures with water, does not detonate or undergo an explosive reaction if heated, and does not detonate or decompose explosively at standard temperature and pressure. The waste is not cyanide- or sulfide-bearing and does not contain 2,4,5-trichlorophenol at concentrations exceeding the dangerous waste limits. The only toxic gas observed in the headspace above the TLV-TWA is $\mathrm{NH}_{3}$. The process wastes retrieved from the tank will require a dilution factor of at least 4.2 (or other mitigation method) to ensure that toxic gases, vapors, or fumes will not be generated at concentrations that are hazardous to human health. 


\subsection{Conclusions}

No exothermic behavior was observed in the majority of the CH-TRUM wastes. Exothermic transitions were observed in a limited number of samples from Tank B-203, and a significant number of samples showed consistent exothermic behavior in Tanks B-202 and T-111. With the exception of the dried samples from Tank T-111, a large endothermic transition was observed between ambient temperature and approximately $150^{\circ} \mathrm{C}$. This transition corresponded to a large mass loss in the TGA, indicating the loss of free water from the sample. This is the major transition in all of the wet sludge samples. A second endothermic transition was observed in many of the samples. This endothermic transition began at about $200^{\circ} \mathrm{C}$ and was due to phase transitions, decomposition of salts or hydroxides, or loss of more tightly bound water. The exothermic transitions that were observed in these samples were generally broad peaks with small amplitudes at temperatures exceeding $200^{\circ} \mathrm{C}$, indicating that explosive reactions or ignition hazards at standard temperatures or pressures are unlikely. The waste with the greatest potential for exothermic reactions is Tank T-111. These reactions would most likely be due to the oxidation of organic compounds that are found primarily in the top section of the waste. One potential source of the organic is the NPH used during core drilling. NPH would float to the top of the waste due to its low density, consistent with the results obtained for this core. One probable reaction is the oxidation of the NPH with the nitrate present in the tank. If these wastes are wet, significant energy must be expended to remove the water from the waste before any reaction can occur.

No data were available on the concentrations of sulfide in these tank wastes, but the sulfur and sulfate analyses indicated that the majority of the sulfur in the waste is present as sulfate. Based on the $\mathrm{pH}$, temperature, and mildly oxidizing conditions of the tank wastes, sulfate is stable and will not react to form sulfide; therefore, the CH-TRUM wastes are not sulfide-bearing.

Limited cyanide analyses were available for these tanks, but the results that were available indicated that these wastes do not contain cyanide at concentrations sufficient to be considered cyanide-bearing wastes. None of these tanks are included on the Ferrocyanide Watch List (Fowler 1993) and cyanide containing wastes and/or process streams were not introduced into any of these tanks.

Concentrations of the 2,4,5-trichlorophenol measured in the CH-TRUM wastes did not exceed the dangerous waste limits; therefore, these wastes do not meet the criteria of a toxic characteristic based on this organic constituent. Oxalate and TOC data indicate that the majority of the organic carbon in the waste exists as oxalate. Based on the existing analytical data obtained from the TWINS database and PNNL and Hanford reports, the CH-TRUM does not exceed the $\mathrm{pH}$ criteria of a corrosive waste.

Gas analysis of the headspace vapors in these tanks and sniff data taken prior to sampling events indicate that all of toxic vapors except $\mathrm{NH}_{3}$ are well below the TLV-TWA. Ammonia is produced in Hanford wastes by several pathways and is retained in the waste due to its solubility in water. The major pathways for ammonia generation include thermal and radiolytic reactions involving nitrite ions and nitrogen-containing complexants (Stock and Pederson 1997). Dilution of the tank wastes prior to retrieval or other mitigation methods will be required to meet this criterion on all of the wastes except those in the B- and T-200 series tanks. 
Analysis of the existing characterization data from core, grab, and vapor samples from the $\mathrm{CH}-$ TRUM wastes supports the removal of the dangerous waste codes for ignitability (D001), corrosivity (D002), and toxicity arising from the presence of 2,4,5-trichlorophenol (D041). For the B- and T-200 series tanks, the data also supports the removal of the dangerous waste codes for reactivity (D003). All constituents and properties were below the levels required to remove waste code D003 from Tanks T-104, T-110, and T-111 except ammonia, which exceeds the TLV in the headspaces of these tanks. 


\subsection{References}

Agnew SF, J Boyer, RA Corbin, TB Duran, JR FitzPatrick, KA Jurgensen, TP Ortiz, and BL Young. 1997a. Hanford Tank Chemical and Radionuclide Inventories: HDW Model Rev. 4. LA-UR-96-3860, Los Alamos National Laboratory, Los Alamos, NM.

Agnew SF, RA Corbin, TB Duran, KA Jurgensen, TP Ortiz, and BL Young. 1997b. Waste Status and Transaction Record Summary (WSTRS), Rev. 4. LA-UR-97-311 Rev. 0, Los Alamos National Laboratory, Los Alamos, NM.

Anderson JD. 1990. A History of the 200 Area Tank Farms. WHC-MR-0132, Westinghouse Hanford Company, Richland, WA.

Brevick CH, JW Funk, and JL Stroup. 1997. Historical Tank Content Estimate for the Northwest Quadrant of the Hanford 200 West Area. HNF-SD-WM-ER-351 Rev. 1, Fluor Daniel Northwest Inc., Richland, WA.

Dupont. 1944. Hanford Technical Manual. Section C. Separations. HW-10475-C, General Electric Hanford Atomic Products Operation, EI DuPont de Nemours \& Company, Inc., Richland, WA.

Fowler KD. 1993. Ferrocyanide Tank Waste Stability. WHC-EP-0347 Supplement 2, Westinghouse Hanford Company, Richland, WA.

Hanlon BM. 2002. Waste Tank Summary Report for Month Ending February 28, 2001. HNF-EP-0182 Rev. 167, CH2M HILL Hanford Group, Inc., Richland, WA

Heasler PG, KM Remund, JM Tingey, DB Baird, and FM Ryan. 1994. Tank Characterization Report for Single-Shell Tank B-201. PNNL-10100, Pacific Northwest National Laboratory, Richland, WA.

Huckaby JL and DR Bratzel. 1995. Tank 241-T-111 Headspace Gas and Vapor Characterization Results for Samples Collected in January 1995. WHC-SD-WM-ER-509, Westinghouse Hanford Company, Richland, WA.

Johnson ME. May 2003. Origin of Waste in Single-Shell Tank 241-T-104. RPP-16129, CH2M HILL Hanford Group, Richland, WA.

McKinney SG, LR Webb, LP Markel, and MA Bell. 1993. Single-Shell Tank Characterization Project and Safety Analysis Project Core 31 and 33, Validation Report Tank 241 T 111. WHC SD WM DP 024 Rev. 0, Westinghouse Hanford Company, Richland, WA.

Osborne JW and LL Buckley. 1995. Data Quality Objectives for Tank Hazardous Vapor Safety Screening. WHC-SD-WM-DQO-022 Rev. 2, Westinghouse Hanford Company, Richland WA. 
Pool KH, JC Evans, BL Thomas, KB Olsen, JS Fruchter, and DKL Silvers. 1996. Headspace Vapor Characterization of Hanford Waste Tank 241-T-104: Results from Samples Collected on 02/07/96. PNNL-11165, Pacific Northwest National Laboratory, Richland, WA.

Stock LM and LR Pederson. 1997. Chemical Pathways for the Formation of Ammonia in Hanford Wastes. PNNL-11702 Rev. 1, Pacific Northwest National Laboratory, Richland, WA.

Tingey JM, J Gao, CH Delegard, LM Bagaasen, and BE Wells. 2003. Physical Property and Rheological Testing of Actual Transuranic Waste from Hanford Single-Shell Tanks. PNNL-14365, Pacific Northwest National Laboratory, Richland, WA.

Washington State Department of Ecology. April 2003. "Dangerous Waste Regulations." Chapter 173303-WAC, Publication Number 92-91, Washington State Department of Ecology, Olympia, WA.

WHC. 1993. 222-S Laboratories Single Shell Tank Waste Characterization, Tank T-104, Cores 45 and 46 Data Package. WHC-SD-WM-DP-032 Rev. 0, Westinghouse Hanford Company, Richland, WA.

WHC. 1994. Tank Farm Waste Compatibility Program. WHC-SD-WM-OCD-015 Rev. 0A, Westinghouse Hanford Company, Richland, WA.

WHC. 1995. Tank Characterization Report for Single-Shell Tank 241-B-202. WHC-SD-WM-ER-371, Westinghouse Hanford Company, Richland, WA. 


\section{Appendix}

Core Sample Profiles 


\section{Appendix \\ Core Sample Profiles}

T-110 RMCS CORE PROFILE

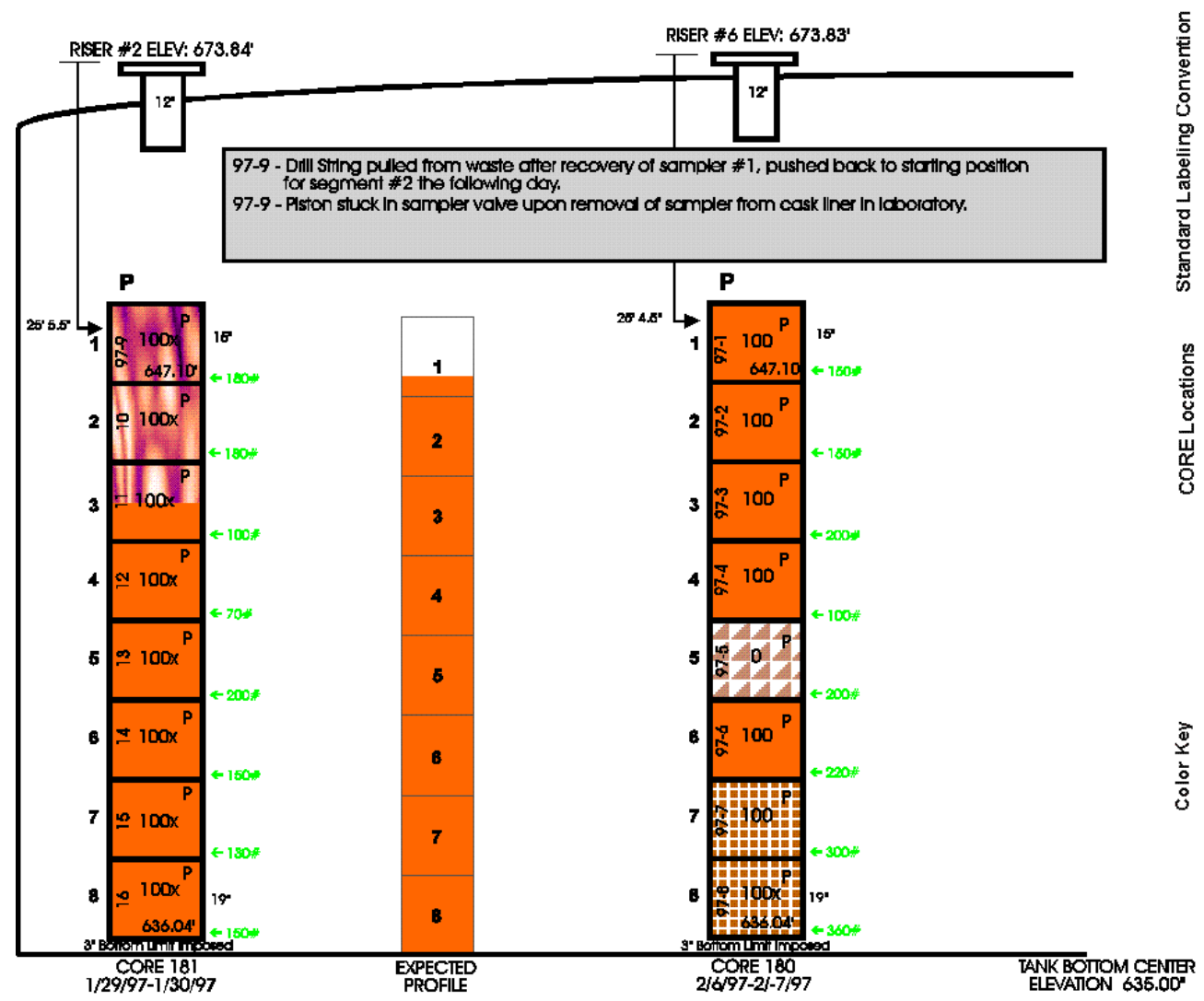

FILE: T110.CRD

DATE: $\quad 4 / 4 / 97$

Profile reflects primary

parameters for each sample. gata nay be adjusted

as previous water additions.

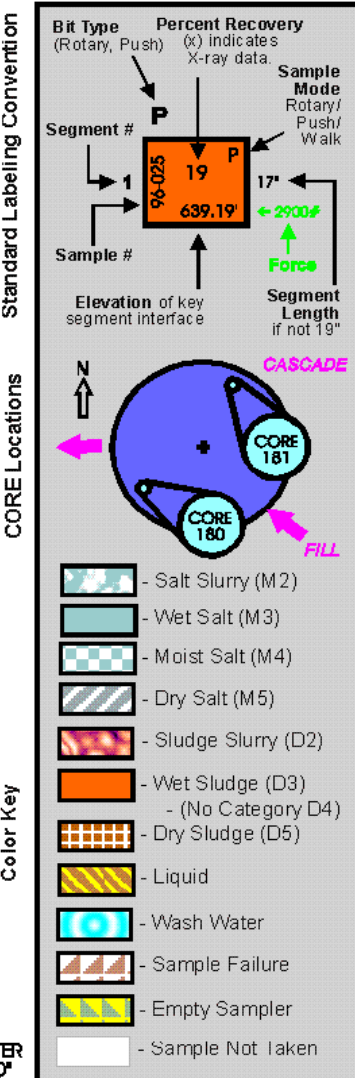

Figure A.1. Tank T-110 Core Profile 


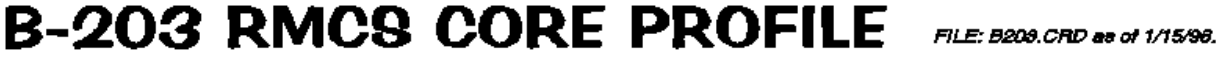

Profiles below indicate primary constituent in sampler and are intended to reflect tank waste conditions. In some instances, extrusion information $m$ ay be a diusted knowing other key information such as previous water additions.
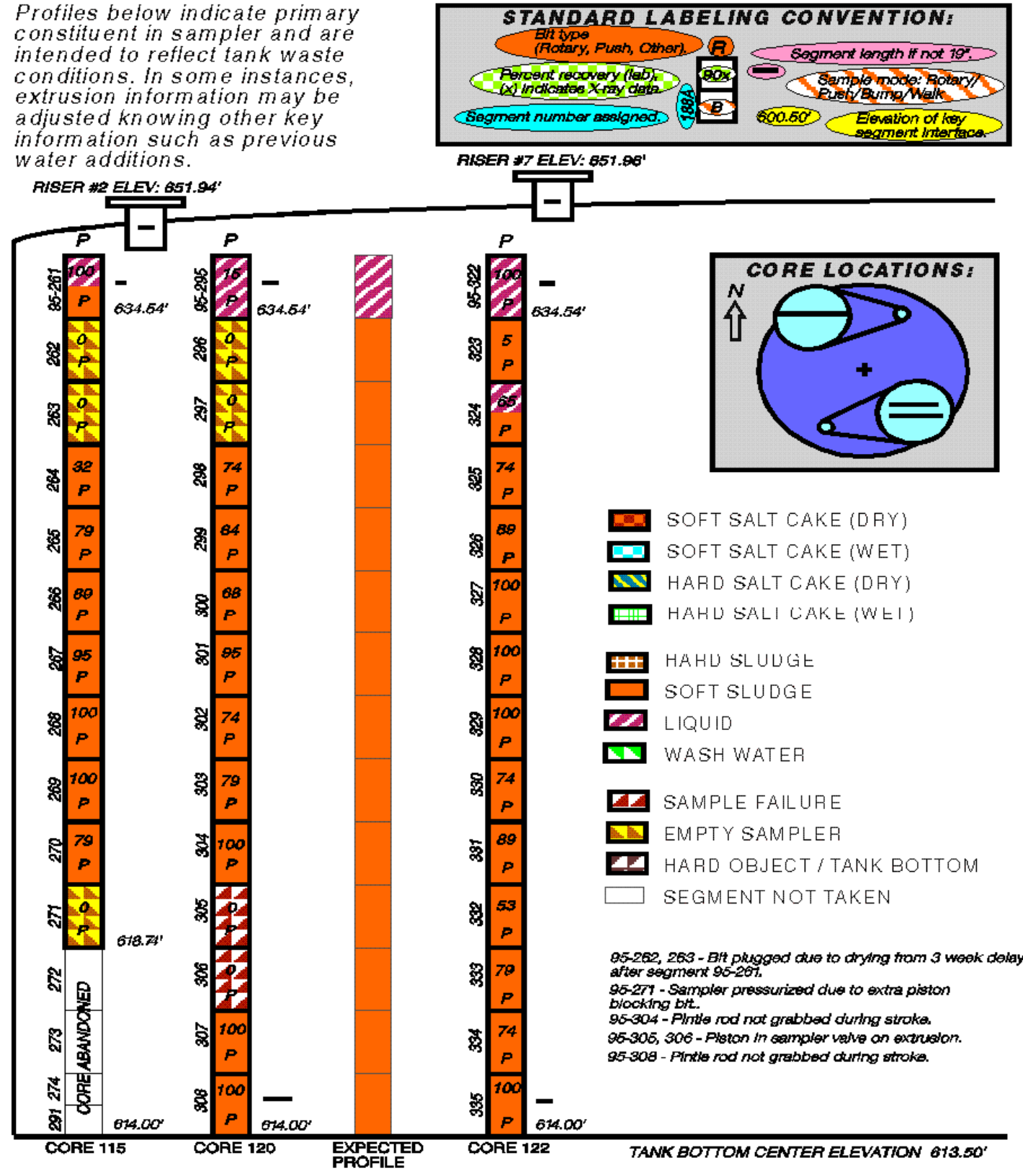

TANK BOTTOM CENTEA ELEVATION GOO.65"

Figure A.2. Tank B-203 Core Profile 


\section{B-204 PMC9 CORE PROFILE}

Profiles below indicate primary constituent in sampler and are intended to reflect tank waste conditions. In some instances, extrusion information may be adjusted knowing other key information such as previous water additions.

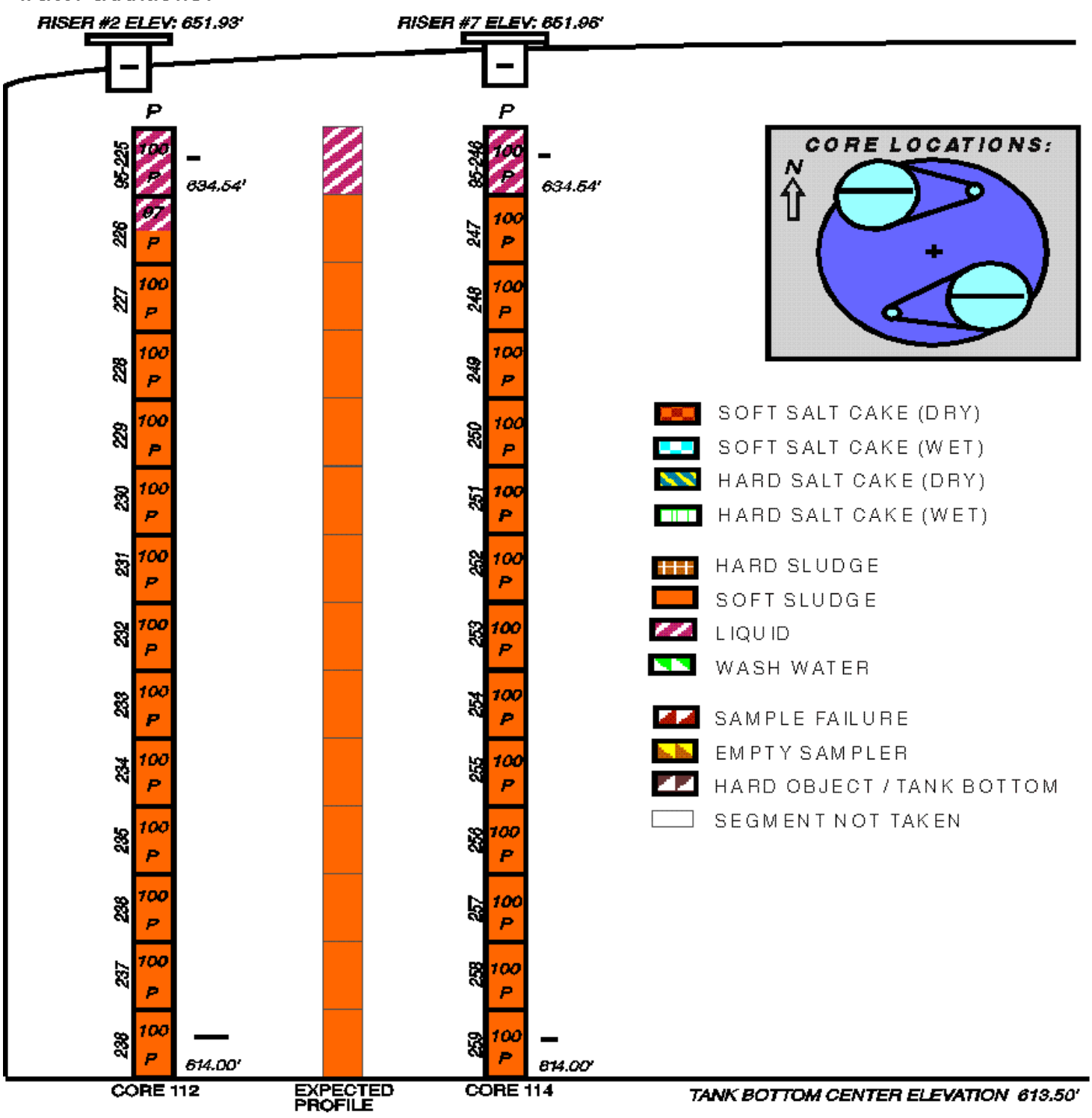

Figure A.3. Tank B-204 Core Profile 


\section{T-201 RMCS CORE PROFILE \\ FILE: T201.CRD}

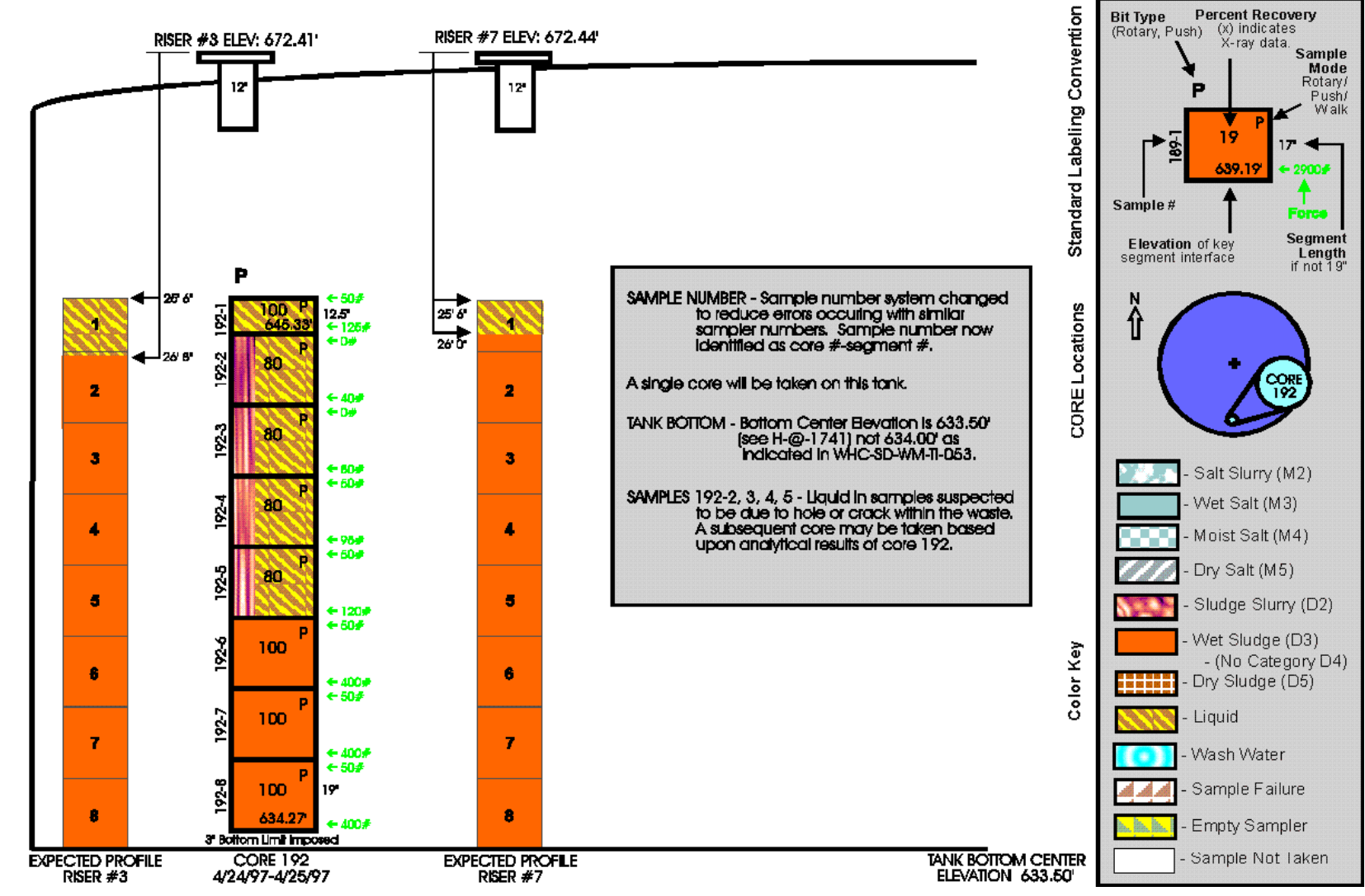

Profile reflects primary parameters for each sample. Dafa may be adjusted given information such as previous water additions.

Figure A.4. Tank T-201 Core Profile 


\section{T-202 RMC8 CORE PROFILE \\ FILE: T202.CRD}

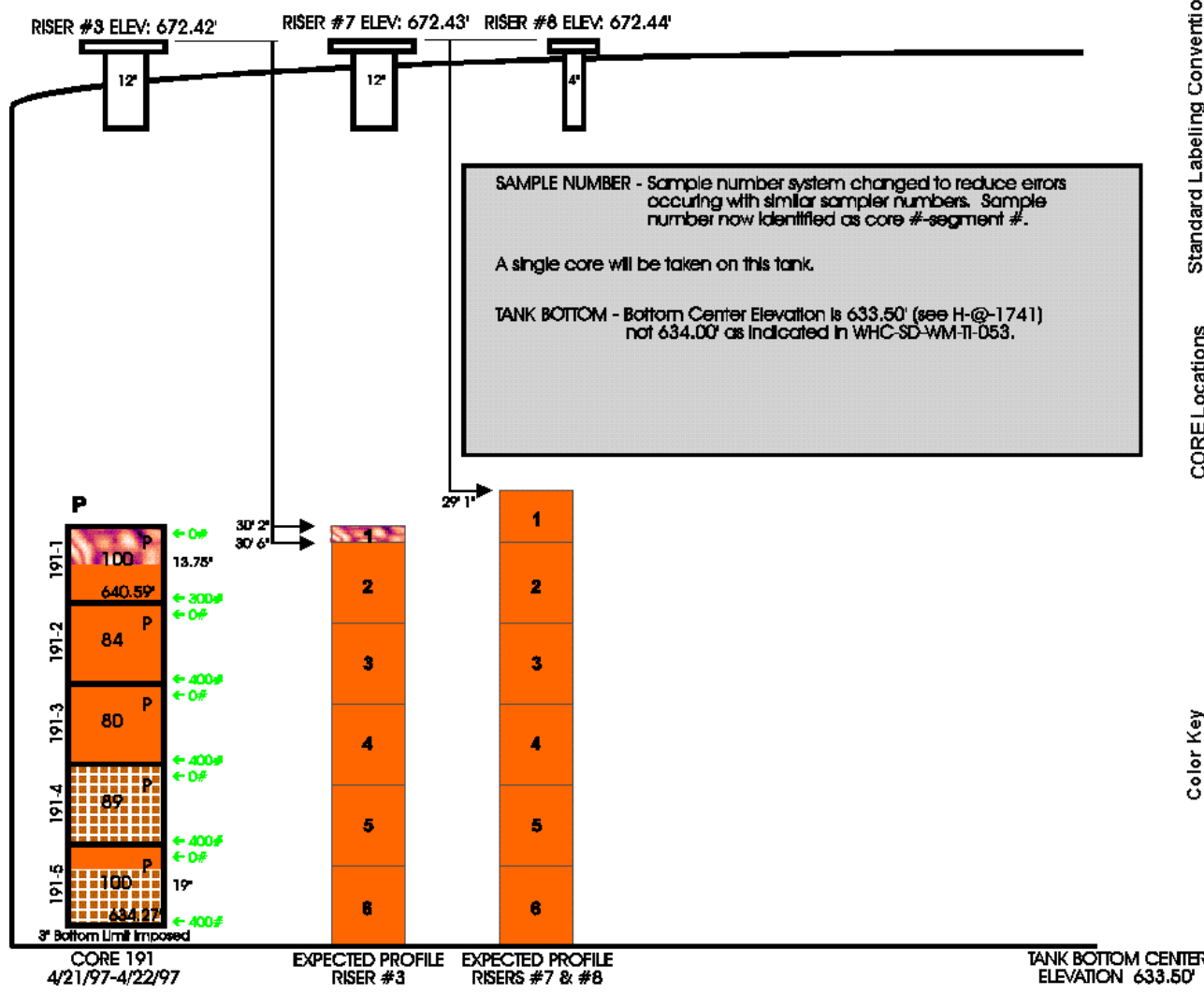

Profile reflects primary

parameters for each sample.

Data may be adjusted

as previous water addifions.

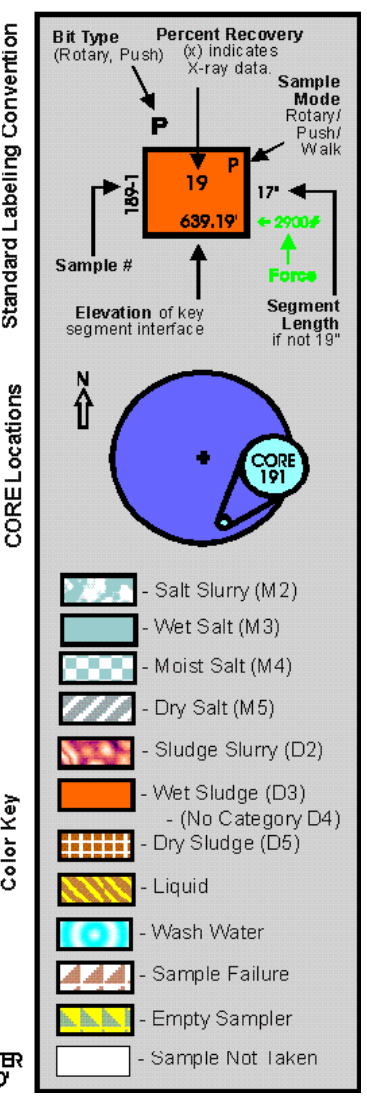

Figure A.5. Tank T-202 Core Profile 
T-203 RMCS CORE PROFILE FILE: T203.CRD

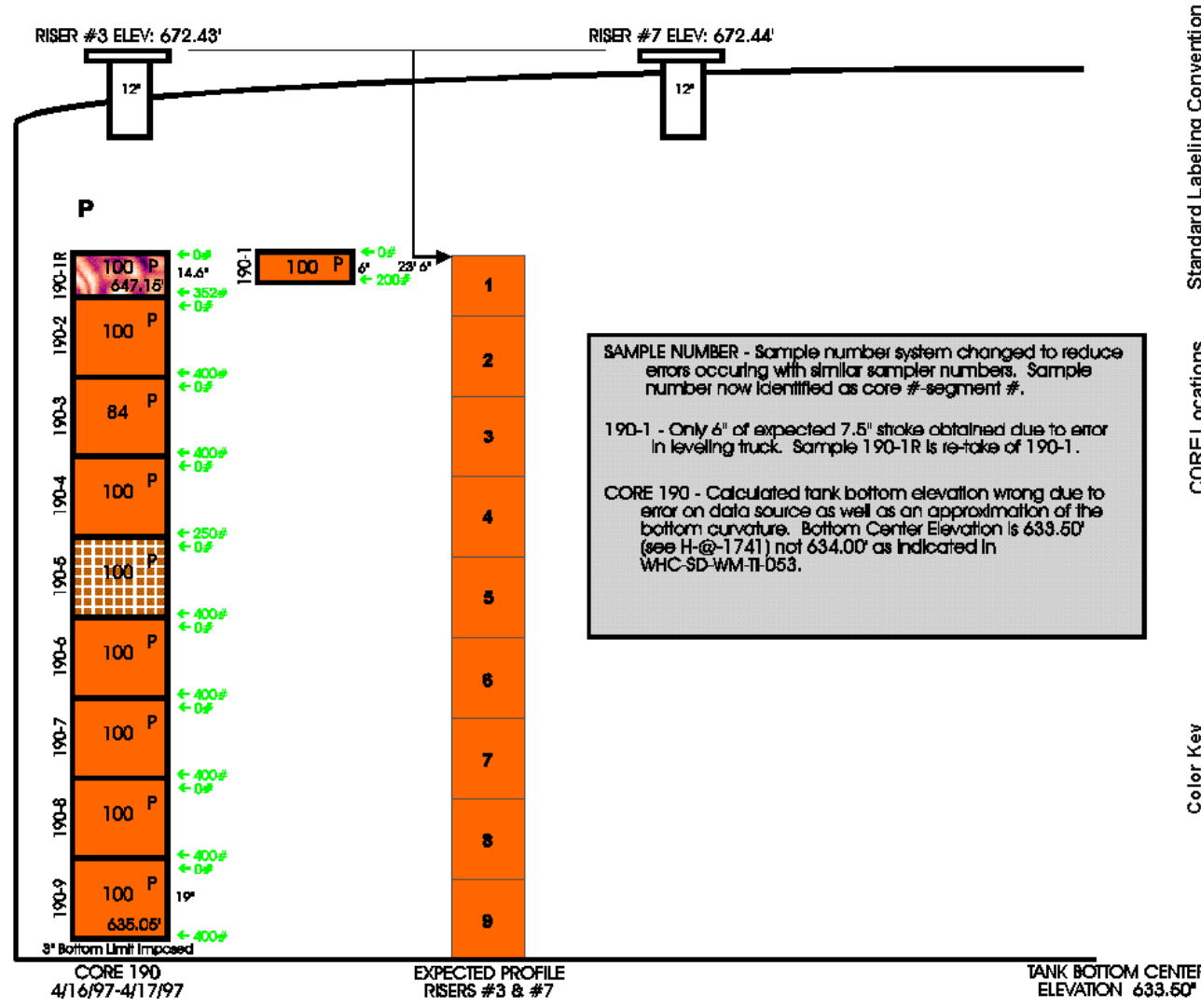

Profile reflects primary parameters for each sample. Data may be adjusted given information such as previous water additions.

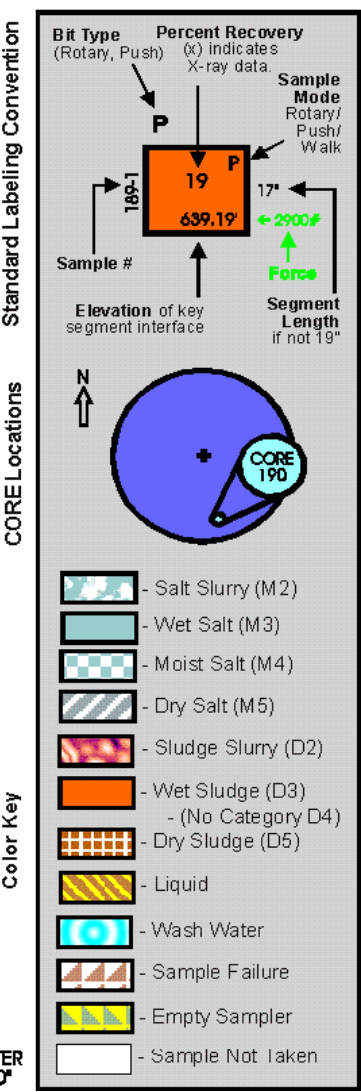

Figure A.6. Tank T-203 Core Profile 


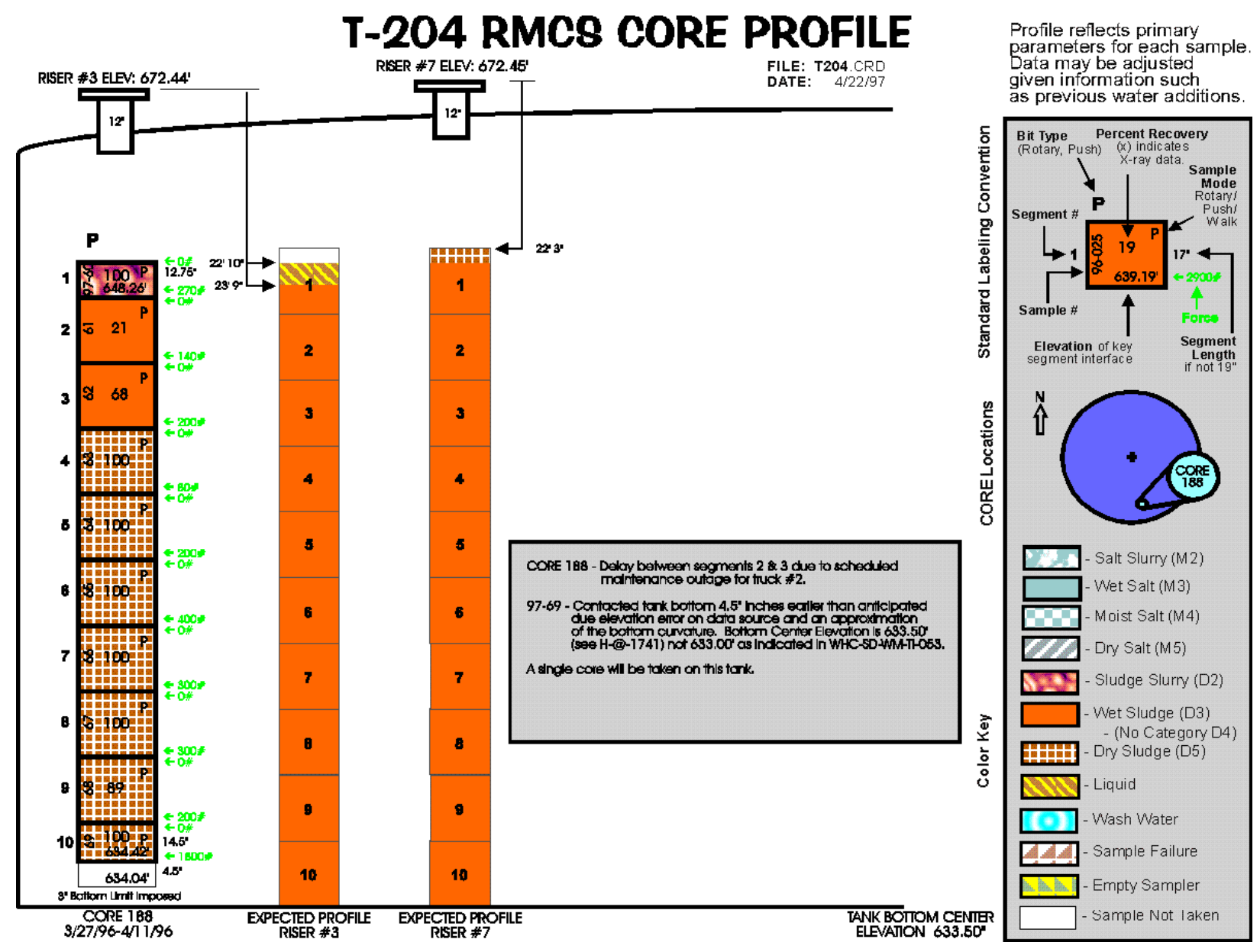

Figure A.7. Tank T-204 Core Profile 
PNNL-14832 Rev. 1

\section{Distribution}

No. of

Copies

ONSITE

DOE Richland Operations Office

BM Mauss

$10 \mathrm{CH} 2 \mathrm{M}$ HILL

KD Boomer

PM Branson

WE Bryan

ME Johnson

JG Kristofzski

RE Raymond

DB Smet

AR Tedeschi (3)
No. of

Copies

27 Pacific Northwest National Laboratory

LM Bagaasen (3)

K6-28

SQ Bennett

K6-50

TM Brouns

K9-69

GH Bryan

P7-25

CH Delegard

P7-25

JR Deschane

P7-25

H6-19

S7-12

GB Josephson

K6-69

ME Lerchen

K6-75

H6-19

LA Mahoney

K7-15

GK Patello

P7-27

AP Poloski

P7-25

SD Rassat

K6-28

RL Russell

K6-24

JM Tingey (10)

P7-25

Information Release (2)

K1-06

Distr.1 